Aus dem Institut für Anatomie nnd Physiologie der Haustiere der Hochschule für Bodenkultur in Wien.

\title{
Beiträge zur Kenntnis des feineren Baues des Gehörorgans mit besonderer Berücksichtigung der Haussäugetiere.
}

Von

Priv.-Doc. Dr. Walther Kolmer, Assistent am Institut.

Hierzu Tafel XXXVII-XL.

Die vorliegende Untersuchung will mit Hilfe verschiedenster, alterer und neuerer Methoden die mikroskopische Anatomie und die Cytologie des Endorganes des achten Hirnnerven einer năheren Betrachtung unterziehen. Speziell sollen die eigentlichen Sinneszellen und der Nervenendapparat, wie wir ihn bei den höheren Säugern und beim Menschen vorfinden, einer näheren Untersuchung zugeführt werden, die Verhältnisse niederer Wirbeltiere sollen vergleichsweise nur dort herangezogen werden, wo die an ihnen klarer hervortretenden Details das Verstandnis der bei böher stehenden Formen gefundenen Tatsachen erleichtert.

Wahrend früher die Untersuchung des Gehörorgans nur in einer mehr oder weniger groben anatomischen Gliederung bestand, sind eigentliche histologische Untersuchungen in heutigem Sinne erst in den fünfziger Jahren des verflossenen Jahrhunderts angestellt worden. Die bisher vorliegenden Arbeiten über das innere Ohr der Wirbeltiere sind sehr zahlreich; sie behandeln aber durchaus nicht in gleichmässiger Weise die verschiedenen Wirbeltiere. Besonders vernachlăssigt sind bisher die grossen Säuger. Die Grïnde dafür sind naheliegend. So ist begreiflich, dass speziell das Gehörorgan des Menschen häufig Gegenstand der Untersuchung war, ebenso, dass die gebräuchlichen Untersuchungsobjekte unserer Laboratorien, vor allem Frosch, Taube, Kaninchen und Hund, viel und oft bearbeitet wurden. Dagegen stellten sich der Zergliederung des Gehörorgans der grossen 
Sauger schon wegen der Härte der das Sinnesorgan umschliessenden Knochenteile grosse Hindernisse in den Weg.

Am besten ist die Form der das Sinnesorgan umgebenden Hohlräume, das knöcherne Labyrinth, bekannt. Auch sind in dieser Beziehung Repräsentanten fast aller wichtigen Wirbeltierordnungen durchforscht worden, da ja naturgemäss die Untersuchung an den haltbaren, knöchernen Gebilden verhältnismässig leicht und einfach war. Ganz anders aber liegen die Verhältnisse, wenn wir das eigentliche Sinnesorgan, das hăutige Labyrinth, betrachten; hier sind die Schwierigkeiten der Untersuchung so eigenartige und fast unüberwindliche, dass es nicht Wunder nehmen darf, wenn die bisherigen Bearbeiter dieses Gegenstandes, nachdem sie die wesentlichen Verhaltnisse bei gewissen Typen der Wirbeltierordnungen festgestellt hatten, die Untersuchung derjenigen Arten, deren anatomischer Bau schwer zuganglich war, unterliessen. Die Härte und Sprödigkeit der einschliessenden Knochenteile, die Zartheit der eingeschlossenen Gebilde, die Unmöglichkeit, sich in vornhinein über die Lage der einzelnen aufzusuchenden Teile genau zu orientieren, waren dem Studium des feineren Baues des Labyrinthes dieser Tiere bisher binderlich. Man begnügte sich mit der Darstellung von Knochenausgüssen oder mit der Beschreibung der Form des häutigen Labyrinths, wie es sich bei Embryonen ohne grosse Mühe herausprăparieren liess.

So erklärt es sich, dass speziell das Gehörorgan unserer Haustiere eine in cytologischer Hinsicht eingehende Darstellung noch nicht gefunden hat.

Was aber den feineren histologischen Aufbau des Labyrinths betrifft, waren die technischen Hindernisse so grosse, dass, abgesehen von einzelnen an Amphibien und Vögeln angestellten Untersuchungen, diese Strukturen von den meisten Bearbeitern nur bei Nagern und Fledermäusen beschrieben, Vergleichsobjekte tieferer und höherer Vertebraten indessen nur in Ausnahmsfällen. herangezogen wurden. Dies gilt sowohl für die eigentliche Cytologie des Labyrinths und seine Cytogenese als insbesondere für das Studium der Nerven und ihrer Endigungsweise. Wenn man von den gross angelegten Forschungen Retzius (40) absieht, die viel vergleichend-histologisch Neues brachten, wurden gerade in den letzten Jahrzehnten immer wieder dieselben Objekte aus technischen Rücksichten der Betrachtung unterzogen. 


\section{Technik.}

Kaum bei irgend einem anderen Organ im Tierreiche stellen sich dem Untersucher bei der Beobachtung so grosse und mannigfache Hindernisse in den Weg, wie bei der Erforschung des Labyrinths der Wirbeltiere, insbesondere aber der Säuger. Da es nicht möglich ist, die gegenseitigen Lagebeziehungen der einzelnen wichtigen Partien im frischen Zustande festzustellen, und auch die cytologische Untersuchung an frischem Material nur wenig Aufschlüsse gibt, ist man darauf angewiesen, fast alles an fixierten Präparaten zu studieren. Dabei sind es höchst mannigfaltige, sehr verschieden gebaute Gewebe, welche hier auf einen kleinen Raum zusammengedrängt sind und trotz weitgehender Unterschiede in ihren physikalischen und chemischen Eigenschaften gemeinsam mit denselben Reagentien behandelt werden müssen, wenn man nicht vorzieht, die Organe gleich zu Beginn der Untersuchung zu zergliedern, was aber auch nicht unbeträchtliche Schwierigkeiten in sich schliesst. Es ist im Gehörorgan der Wirbeltiere in einem mit. Flüssigkeit erfüllten Hohlraumsystem ein zweites mit Flüssigkeit gefülltes Hohlraumsystem untergebracht, und beide sind mit ihren zarten und sehr elastischen Wandungen von fast ganz unelastischen Kapseln umgeben. Bei den einzelnen Wirbeltierordnungen sind diese bald knorpelig, bald knöchern, bei den grossen Säugern ist der Knochen, aus dem sie gebildet werden, so hart, dass dieser als härtester Knochen des gesamten Skeletts den Namen Felsenbein mit Recht trägt.

Es gelingt zwar, wenn einmal die Lage des häutigen Labyrinths bei einem Tier genau bekannt ist, mit einiger Uebung und Zuhilfenahme von Meissel, Knochenzange und Messer, dieses von seiner Hülle zu befreien, doch dürfte es nur selten glücken, dabei die Integrităt der feineren häutigen Hohlrăume zu wahren, da sich nach Wegfall ihrer Befestigungen deren Form und Spannungsverhältnisse bedeutend verändern.

Sieht man von der Untersuchung im frischen Zustande $a b$, die ja für gewisse Fragen höchst wichtig ist (z. B. die Frage nach der Konsistenz der sogenannten Cupula, der Lage der Hörhaare, der Lage und Spannung der Teile des Cortischen Organs und ihrer Beziehungen zur Membrana tectoria), so ist die Freilegung wenigstens teilweise nötig, um die Flüssigkeiten, welche konservierend wirken sollen, in unmittelbaren und raschen Kontakt mit 
dem häntigen Labyrinth zu bringen, da auch die bestwirkenden Fixierungsmittel nicht schnell genug die knöchernen Wandungen zu durchdringen vermögen. Die eigentlichen Sinneselemente und auch Stützelemente besitzen einen ganz besonders bohen Grad von Verănderlichkeit, wie kaum irgend andere Zellen im tierischen Körper. Ein Fixierungsmittel, welches nicht unmittelbar auf die noch überlebenden Zellen einwirken kann, würde auch kurze Zeit nach Absterben des Gewebes mehr oder minder veranderte geschrumpfte oder gequollene Elemente fixieren und kaum mehr als ein Zerrbild der im Leben bestehenden Formen liefern. Schon um die Anwendbarkeit eines Fixierungsmittels zu prüfen, ist es unbedingt nötig, es wenigstens einmal direkt auf die Gewebe einwirken zu lassen, um die Erscheinungen des postmortalen Zerfalls von durch die Fixierung geschaffenen Veränderungen unterscheiden zu können. Neutrale Fixierungsmittel haben die Eigenschaft, Knochen und Knorpel nur langsam zu durchdringen, săurehaltige Fixierungsmittel, die im allgemeinen besser eindringen, werden auf ihrem Wege durch die Kalksalze des Knochens neutralisiert und verlieren so an Wirksamkeit.

Ein geeignetes Auskunftsmittel, um diese Uebelstände zu umgehen, besteht darin, das hăutige Labyrinth in seiner Kapsel in situ zu belassen und nur an einigen Stellen unter der Fixierungsflüssigkeit den Knochen zu entfernen, um dieser so den Zugang zu eröffnen. Leider hat auch diese verhältnismässig geeignetste Methode den Nachteil, dass die von den hergestellten Öffnungen aus in das hăutige Labyrinth diffundierende Fixierungsflüssigkeit bei ihrer Ausbreitung immer mehr verdünnt wird, ihre beste Wirkung nur an der Stelle des Eindringens entfaltet, die weiter nach innen gelegenen Gewebsteile aber gradatim schlechter fixiert. Man kann dies z. B. kontrollieren, wenn man an einem oder dem anderen Ende des Schneckenkanals den Knochen entfernt. In gewissem Grade versuchte ich diesen Übelstand dadurch zu bekămpfen, dass die Objekte in grossen Mengen des Fixierungsmittels hin und her bewegt wurden.

Von den vielen Fixierungsmitteln, welche zum Studium des Labyrinthes bisher empfohlen worden sind, kann keines als Ideal angesehen werden. Die verschiedenen Gewebsbestandteile, die Epithelien, das ganz eigenartige Bindegewebe, die markhaltigen und marklosen Nerven verhalten sich jedem Reagens gegenüber 
so verschieden, dass man nicht imstande ist, jemals Stütz- und Sinneselemente zugleich mit den Nerven gut fixiert zu erhalten. Die săurehaltigen Fixierungsmittel sind erfahrungsgemåss imstande, schneller kalkhaltige Gewebe zu durchdringen, sie baben aber den Missstand, je nach der Konzentration mehr oder minder heftig an den Knochenpartien Gasblasen zu entwickeln. Diese zerreissen zarte Membranen und verăndern die Lage einzelner Teile, wenn sie sich aus Hohlraumen herauszwängen.

Genügt der Säuregehalt des Fixierungsmittels, um den Knochen vollkommen zu entkalken, so werden schon dadurch die Spannungs- nnd Lageverhăltnisse alteriert.

Ein Mittel, die beiden letzten Übelstände zu vermeiden, ergibt sich dadurch, dass man die fixierten Gewebe vor der Entkalkung mit Celloidin durchtrånkt und so eine Verschiebung der Teile aus ihrer Lage hin anhält. Andererseits wurden Fixierungsmittel empfohlen, die zu gleicher Zeit mit der Fixierung ein sehr schonendes, allerdings auch sehr langsames Entkalken ermöglichen. Alle diese Schwierigkeiten, die sich schon bei kleinen Tieren bieten, sind bei grossen Saugern in noch viel höherem Maße vorhanden, da die Knochensubstanz eine ungleich kompaktere und härtere ist als bei den Objekten, die gewöhnlich bisher zur Untersuchung verwendet wurden (Maus, Meerschweinchen, Fledermaus, Kaninchen, Katze). Speziell bei den Haussäugetieren kommt man mit den zugleich entkalkenden Fixierungsmitteln auch nach Monaten nicht recht zum Ziel, und man muss noch eine eigentliche Entkalkung auf die lange dauernde Fixierung folgen lassen. Von den in Betracht kommenden Sauren, welche leichtlösliche Kalkverbindungen geben, war früher in erster Linie die Salzsăure beliebt. Die Zusătze von Palladiumchlorid einerseits, von Phloroglucin andererseits, welche zur Hintanhaltung störender Veränderungen in den Geweben empfohlen wurden, sind leider nur von zweifelhaftem Wert. Für die spätere Färbung ist Cbromsäure ein geeignetes Entkalkungsmittel; noch besser aber erhält Salpetersăure die Form und Farbbarkeit, besonders der nervösen Elemente.

Die beim späteren Auswaschen leicht auftretende Quellung hat man durch Zusatz von Essigsäure zur Salpetersaure auf A pathys Empfehlung teilweise vermeiden gelernt; noch besser aber wirkt eine Behandlung mit starker Lithiumsulfatlösung - 
wie Schaffer geraten hat - welche man vor dem Auswaschen 24 Stunden auf die entkalkten Gewebe einwirken lässt. Ausser Salpetersäure kamen bei der vorliegenden Arbeit noch Pikrinsäure, Trichlormilchsäure und Trichloressigsäure teils zur Fixierung teils dort zur Entkalkung zur Anwendung, wo eine Silberimprägnation vorausgegangen war. Es ergaben besonders die beiden letztgenannten Säuren die Möglichkeit, gewisse Einschlussgebilde der Sinnesepithelien prägnant zu färben, wie es mit anderen Fixierungsmitteln nicht gelungen war. Auch die Entkalkung vital mit Methylenblau gefürbter Labyrinthe lässt sich, wie bekannt, mit den genannten Säuren ohne Schädigung der Färbung erreichen.

Viele der Übelstände bei der Fixation lassen sich dadurch vermeiden, dass man die Fixierungsflüssigkeit durch Injektion unter leichtem Druck von den Gefässen aus einwirken lässt. Eine Methodik, die schon von Ranvier angewendet, speziell für Sinnesorgane wiederholt von Mann (37) empfohlen wurde. Es wurde dabei folgendermaßen verfahren: Das Tier wurde vollkommen narkotisiert, dann aus der einen Carotis verbluten gelassen, während durch die Carotis der Gegenseite unter mässigem Druck gewärmte Ring e rsche Flüssigkeit, die einen Zusatz von Amylnitrit hatte, peripher eingespritzt wurde. Dann wurden nach Eröffnung der Brusthöhle alle Gefässe ober dem Herzen mit Massenligatur abgebunden, die beiden Jugulares in Klemmen gefasst und eröffnet. Man kann auf diese Weise bei abwechseIndem Öffnen und Schliessen der beiden Jugulares durch die Klemmen auch bei grösseren Tieren ohne Anwendung bedeutenden Druckes oder erheblicherer Flüssigkeitsmengen in drei bis vier Minuten das Blut vollkommen entfernen und spritzt dann die Fixierungsflüssigkeit unter langsam ansteigendem Druck ein, wobei man schliesslich zweckmässiger Weise nach Absperrung der Jugulares den Druck noch etwas erhöht. Bei einiger Übung lernt man es, vollkommen die durch Überdruck entstehenden Ödeme zu vermeiden, besonders wenn man den Druck durch die Tension des Bulbus kontrolliert. So ist es mir gelungen, bei Ziegen das Labyrinth in wenigen Minuten in situ zu fixieren. In derart fixierten Labyrinthen finden wir bemerkenswerter Weise die Membrana tectoria dem Cortischen Organ in allen Windungen nahe angelagert, ein Resultat, das sich bei anderen Fixierungsmethoden niemals sicher voraussehen lässt. 
Im Verlaufe meiner Untersuchung habe ich wohl die meisten der für die Fixierung von Sinnesorganen gebräuchlichen Methoden durchprobiert. Aber nur wenige geben. den gewünschten Erfolg. Dies gilt in erster Linie von den an anderen Objekten mit Recht. so geschätzten osmiumhaltigen Kombinationen, der Fle mmingschen, Hermannschen Flüssigkeit und ähnlichen Gemischen. Sie alle leiden an dem Übelstand, dass durch den Kalk des Knochens die in ihnen enthaltene Säure so schnell neutralisiert. wird, dass sie, auch wenn ihnen durch Eröffnung des knöchernen Labyrinths der Zutritt zum häutigen Organ erleichtert ist, ihre Wirksamkeit nicht mehr entfalten können, und nur Teile, die einigermaßen direkt von ihnen berührt werden, in geeigneter Weise fixiert erscheinen. Immerhin bietet die Osmiumsaure auch heute noch unübertroffene Vorteile für die Fixierung der Zellhaare, speziell in den Ampullen, und für die Darstellung der Markscheiden, besonders auch dort, wo sie an den Zellen der Acusticusganglien dargestellt werden können. Sie muss hochprozentig, nicht weniger als in $2 \%$ Lösung zur Anwendung kommen, wie auch $\mathrm{Kr}$ a use (30) in seiner neuesten Publikation betont. Besser bewähren sich Sublimat in konzentrierter Lösung und die damit. kombinierten Flüssigkeiten, vor allem die schon mehrfach empfohlene Kombination mit Osmiumsäure und Essigsäure. Recht gute Resultate liefert auch Sublimat-Pikrinsaure. Auch die eben erwähnten Fixierungsmittel leiden an dem Übelstand, nur langsam einzudringen. Man muss grosse Mengen von ibnen anwenden und für Erneuerung der Flüssigkeit sorgen. Bei grösseren Objekten, z. B. dem Gehörorgan der erwachsenen Katze, sind sie schon nicht mehr ausreichend, und die häufig entstehenden Sublimatniederschläge lassen sich durch Jodtinktur nicht mehr vollkommen entfernen. Etwa in gleicher Weise verhalten sich die Chloroform und Alkohol enthaltenden Gemische, wie die Carnoysche und ahnliche Flüssigkeiten. Sie bieten nur speziell beim Studium der Ganglien gewisse Vorteile. Auch die Pereny ische Flüssigkeit, die sich bei Untersuchung anderer vergänglicher Sinneselemente, z. B. der Retina, vortrefflich bewährt, gab mir hier keinen Erfolg, sie stellt nur besonders gut die Struktur der Membrana tectoria dar.

In neuester Zeit sind von verschiedenen Seiten (E. M üller, Tellyesnicky, Orth etc.) als besonders günstige Fixierungs- 
flüssigkeiten Kombinationen von Formol-Kaliumbichromat und Eisessig empfohlen worden: $\mathrm{Held}(20)$ hat sich dieser Flüssigkeiten bei seiner umfangreichen Untersuchung anscheinend mit besonderem Vorteil bedient. Ohne $\mathrm{Helds}$ Angabe zu kennen, der leider eine detaillierte Vorschrift bisher noch nicht veröffentlicht hat, habe ich ahnliche Kombinationen versucht und damit wie Held speziell auch für die grossen Săuger ganz besonders günstige Resultate erzielt.

Auch für die früher erwăhnte Injektionsmethode eignet sich dieses Gemisch vortrefflich. Natürlich müssen der Grösse des Objektes entsprechende Mengen zur Anwendung kommen und die Lösung, in der die Objekte längere Zeit verweilen, mehrmals gewechselt werden. Bei kleineren Objekten (Maus, Meerschwein) lässt man diese Fixierungsflüssigkeit $2-3$ Wochen einwirken, bei grösseren Objekten entsprechend länger. Sie hat ausserdem den Vorteil, wie schon Held (20) betonte, in schonendster Weise zu entkalken. Allerdings dauert dabei die Entkalkung grosser Objekte recht lange, so dass ich meist nach den ersten Wochen durch Zusatz von Salpetersăure bis zu 5 pCt. dieselbe beschleunigte. Alle Sinneselemente, speziell im Cortischen Organ, aber auch Stützelemente und Nerven werden dabei vorzüglich erhalten und gestatten eine ausgezeichneteDifferenzierung der protoplasmatischen Details, Stützsubstanzen etc. Vom Chromgehalte der Lösung ist es abhängig, ob man mehr das Bild homogener Markscheiden erhalt oder dasjenige von Neurokeratinstrukturen.

Für die Darstellung der Maculae und Cristae gibt auch diese Flüssigkeit meines Erachtens keine vollkommenen Resultate, was mir auch an den Bildern $\mathrm{Helds}$ bezüglich dieser Objekte hervorzutreten scheint. Eine kurze, vorhergehende Räucherung mit Osmiumsäure der teilweise im Knochen frisch freigelegten hăutigen Labyrinthpartien kann die Resultate wesentlich verbessern.

Was die Einbettung betrifft, so wurden kleine Objekte bis zu $4 \mathrm{~mm}$ Kantenlänge in Paraffin eingebettet, grössere Objekte ausschliesslich in Celloidin. Die Objekte, auch die nach den Cajalschen Methoden behandelten, gingen drei Tage durch Alkohol steigender Konzentration und blieben 12 Stunden in zweimal gewechseltem absoluten Alkohol, dann kamen sie in zweimal gewechseltes Cedernöl auf 24 Stunden und wurden schliesslich durch Tetrachlorkohlenstoff in weiches Paraffin ein- 
gebettet, dieses dreimal nach je $1 / 2$ Stunde gewechselt und schliesslich durch $58^{\circ}$ Paraffin ersetzt, in welchem die Objekte nur $1 / 2$ Stunde verweilten.

Was die Färbung der Präparate betrifft, so scheint mir bei den mit osmiumbaltigen Fixierungsmitteln behandelten Objekten starkes Osmieren und Nachbehandlung mit rohem Holzessig recht befriedigende Färbungen zu geben.

Sollte in anderer Weise gefärbt werden, wurden die Schnitte mit $\mathrm{H}_{2} \mathrm{O}_{2}$ (M e rcks Perhydrol) behandelt, bis sie vollkommen entfärbt waren. Solche Objekte wurden dann so wie meist auch alle auf andere Weise fixierten mit Eisenhämatoxylin nach Heidenhain gefärbt. Diese Färbung wurde speziell für das Gehörorgan in einer komplizierten Weise von Held modifiziert, welcher ohne genauere Angabe zur Beize neben Eisenalaun, Chromalaun und Alsol empfabl, zur Färbung Molybdänhämatoxylin. Es ist mir nicht gelungen, mit Modifikationen in dieser Richtung bessere Differenzierungen $\mathrm{zu}$ erreichen, als mit der gewöhnlichen Eisenhämatoxylinfärbung bei genügend vorsichtiger Differenzierung. Denn es gelang mir auch mit der letzteren an lange, mit Kaliumbichromat-Formol-Eisessig fixierten Objekten die Stützstrukturen in den Epithelien, wenn auch etwas weniger gut die marklosen Nerven zur Darstellung zu bringen. Speziell bei abwechselndem Differenzieren mit verdünntem, salzsaurem Alkohol und Eisenalaunlösung hat man es in der Hand, diese Strukturen besonders scharf hervortreten zu lassen. Nach der Differenzierung blieben die Schnitte, wie Heidenhain es empfohlen hat, über Nacht in Chlorammoniumlösung, wodurch die Färbung haltbarer wurde.

Neben Eisenhämatoxylin wurde auch Apathys Haematein und Thionin und die Weigertsche Markscheidenfarbung mit Vorteil verwendet.

Häufig wurde eine Doppelfärbung vorgenommen. Ich benutzte dazu meist Rubin $\mathrm{S}$, oder auch das von $\mathrm{He}$ id en hain empfohlene Kongokorinth oder auch letztere beide mit nachheriger Färbung in prikrinsaurem Alkohol. Speziell werden durch letztere Methode viele feine Details in der Membr. basilaris, in der M. tectoria, dem Limbus spiralis und in verschiedenen bindegewebigen Teilen gut hervorgehoben, ohne dass dabei die durch Eisenhämatoxylin dargestellten Strukturen an Deutlichkeit eingebüsst hätten. 
Da meine Bemühungen speziell darauf gerichtet waren, den Verlauf der Nerven und der Neurofibrillen in ihnen und deren Beziehungen zu den Sinneszellen darzustellen, wurden diejenigen Methoden versucht, welche einerseits Übersichtspräparate über den Verlauf einzelner Fasern auf längere Strecken liefern, wie die Chromsilberimpregnation und die vitale Methylenblaufärbung, andererseits diejenigen Methoden herangezogen, welche zur Darstellung der Neurofibrillen geeignet erschienen: die Methoden von Bielschowski (4) und Cajal (7).

Die Chromsilbermethoden haben im Gehörorgan speziell den Nachteil, ausser den Nerven noch allerlei andere Gebilde und diese im Zusammenhang zu imprägnieren, wie man auch aus den teilweise widersprechenden Resultaten entnehmen kann, die z. B. Retzius (41), Lenhossek (34) und Ayers (3) mit dieser Methode erhalten haben. Auch eignet sie sich nur für Embryonen oder kalkarme Objekte neugeborener kleiner Tiere. Es kam daher diese Methode von vornherein weniger in Betracht.

Die vitale Methylenblaufärbung ergab in einer grossen Anzahl von Versuchen, die an Kaninchen und Katzen ausgeführt wurden, bei Injektion ins Gefässsystem recht unbefriedigende Resultate. Etwas bessere bei Einwirkung des Methylenblaus nach dem Vorgange Dogiels auf direkt freipräpariertes häutiges Labyrinth in Ringerscher Lösung oder Serum. Auf diese Weise lasst sich auch manches beim Pferd und Schwein erzielen. Eine befriedigende Fixierung der gefärbten Elemente mit den verschiedensten dazu empfohlenen Methoden gelang nicht, auch osmiumhaltige Flüssigkeiten vermochten den Übelstand nicht zu beseitigen. Viel bessere Resultate lieferten die neueren Methoden zur Darstellung der Achsenzylinder und seiner Neurofibrillen.

Die Methoden Bielschowskis (4) wurden nach seinen ălteren und neueren Angaben mit Erfolg angewendet. Sie eigneten sich gut, speziell zur Darstellung der Achsenzylinder im Gebiete der Schneckenachse bei Embryonen und jungen Tieren. Die Färbung der Neurofibrillen gelang auch in den Ganglienzellen meist befriedigend, versagte aber meist im Bereiche der Sinneszellen. Besonders günstig erwies sich die Methode an Gefrierschnitten. Es wurde mit Formol (bei Embryonen), mit FormolOsmium-Salpetersäure oder Formol-Salpetersäure bei grösseren Tieren fixiert und die Gefrierschnitte mit Hilfe eines Kohlensäure- 
Mikrotoms entweder ohne Einbettung oder nach Einbettung in Gelatine, die mit Formol nachgehärtet wurde, hergestellt. Mit jenen Modifikationen der Methodik, die Bielschowski und Wolff (5) in neuerer Zeit empfohlen haben, konnte ich zu keinerlei befriedigenden Resultaten kommen. Mit besonderem Erfolg aber bewährte sich die Cajalsche Methodik, und zwar in ihren beiden Modifikationen bei direkter Fixierung mit Silbernitrat oder bei vorausgehender Fixierung mit ammoniakalischem Alkohol. Dabei wurde folgendermassen vorgegangen:

Die Objekte (kleine Embryonen in toto, von grösseren der Kopf, von neugeborenen Tieren die halbierte Schädelbasis oder nur das Felsenbein) wurden in etwa $50 \mathrm{ccm} 2 \mathrm{pCt}$. Silbernitratlösung eingelegt (stärkere Konzentrationen, wie sie von Cajal empfohlen wurden, ergaben keinen nennenswerten Vorteil in bezug auf Erhaltung der Zellelemente). In dieser Lösung blieben sie im Dunkeln im Brutschrank bei einer Temperatur von $30-33^{\circ}$ 4 mal 24 Stunden. Dann wurden die Objekte kurz mit Aqua destillata abgespült und in der von $\mathrm{Caj}$ a l angegebenen Flüssigkeit (Formol-Pyrogallol oder Formol-Hydrochinon) 24 Stunden reduziert. Bei der Vorbehandlung mit ammoniakalischem Alkohol wurde dieser zwei Tage einwirken gelassen und mehrfach erneuert. Dann wurden die Objekte $12-24 \mathrm{~h}$ mit Aqua destillata ausgewaschen und kamen in eine $1 / 3-1 \%$ ige Silbernitratlösung auf acht Tage in den Brutschrank. Nach der Reduktion in FormolPyrogallussăure wurden sie schliesslich in Paraffin oder Celloidin eingebettet und in Schnittserien zerlegt. Für das Gelingen der Methode ist es von Wichtigkeit, dass das Material möglichst frisch sei und dass genügend grosse Mengen der Silberlösung, mindestens das 50 fache Volumen des Objekts, zur Anwendung gelangen. Der Verwendung schon gebrauchter Silberlösung möchte ich widerraten, da sie die Methode unsicher macht. Die geschilderte Methodik erzielt dort überall gute Resultate, wo geringe Dimensionen der Objekte die direkte Einwirkung der Reagentien gestatten und ein Entkalken sich vermeiden lässt. Speziell eignet sich dazu die Maus und ibre Embryonen. Ganz junge Embryonen und über 20 Tage alte Măuse geben schlechte Resultate. Allerlei Modifikationen der geschilderten Methodik, wie Vorfixation mit Formol oder Zusătze von Osmiumsäure, um die Hörhaare besser zu konservieren, erwiesen sich als nicht zweckentsprechend, da Archiv f. mikrosk. Anat. Bd. 70. 
in so vorbehandelten Geweben das Fibrillenbild nicht zustande kommt. Bei grösseren Tieren muss man das Silber direkt auf das mit möglichster Schonung vollkommen frei prăparierte båutige Labyrinth einwirken lassen und erzielt damit gute Erfolge auch bei grossen Saugern und beim Menschen. Der ammoniakalische Alkohol steht aber als Konservierung noch hinter der Silbernitratlösung zurück.

Am Cortischen Organ erwachsener Tiere scheitern die Methoden bisher leìder vollkommen, da alle Eingriffe, die den Ductus cochlearis präparativ den Reagentien zuganglich machen, die Gebilde des Cortischen Organs im unfixierten Zustand zerstören und die zur Anwendung kommenden Reagentien zur Fixation nicht ausreichen. Man ist also, bis man eine geeignete Modifikation der Methode besitzen wird, darauf angewiesen, das Cortische Organ bei kleinen Tieren, vor allem Maus, Ratte, Fledermaus zu studieren.

Die Fibrillenmethode Bethes und deren Modifikationen ergaben für das Gehörorgan kein günstiges Resultat.

\section{Anatomischer Aufbaudes Gebörorgans.}

Wie schon eingangs hervorgehoben wurde, hat die Struktur des Labyrinths der höheren Săuger und speziell der Haustiere bisher weniger Behandlung erfahren, als die der kleineren Säuger und des Menschen.

Besser orientiert sind wir über die Gestalt des knöchernen Labyrintbs und über die makroskopischen Formverhăltnisse des häutigen Labyrinthes dieser Tiere.

Was die Formverhältnisse des knöchernen Labyrinthes betrifft, so habe ich den Darstellungen der Autoren kaum etwas Wesentliches hinzuzufügen.

Die Gestalt des Labyrinthes bei den Wiederkäuern hat zuerst durch Carl (9) eine Darstellung erfahren. Retzius (40) hat in seinem grossen klassischen Werke auch die häutigen Labyrinthe vom Schwein und Rind dargestellt. Neuerdings wurde von De nker (12) deren Gestalt an Corosionspráparaten und Knochenschnitten, sowie auch das Labyrinth des Pferdes detailliert beschrieben. Messungen der Bogengange sind bei Wiederkăuern, speziell dem Kalb, von Biner Wulf (46) angestellt worden. 
Schwe in.

Das Os petrosum ist beim Schwein nicht nur bei jungen Tieren, sondern auch bei alten ausgewachsenen Exemplaren durch zarte Verbindungen mehr bindegewebiger Natur mit den übrigen Knochenpartien des Schläfenbeines verwachsen. Es lässt sich daher vom Innenraum des Schädels nach Ablösung der Dura mater ohne Anwendung grösserer Gewalt von ihnen trennen. Dieses ist für die Untersuchung vom grössten Vorteil.

Die untere Gegend des Promontoriums ist, wie Denker (12) es auch hervorhebt, meist nicht vollkommen verknöchert, so dass die Kuppel der Schnecke nur durch zart mit Knochensubstanz durchzogenes Bindegewebe überdeckt erscheint, ein weiterer Umstand, der die Fixierung des Labyrintbs etwas erleichtert. Auch prominiert die Schnecke etwas in die Paukenhöhle hinein, was die Orientierung bei der Praparation erleichtert. Die leichte Zugänglichkeit des Materials veranlasste mich, speziell das Labyrinth des Schweines einer näheren Untersuchung zu unterziehen und speziell das Cortiscbe Organ und die anderen Nervenendstellen zu untersuchen. Nach Denkers Angabe misst die Basis des knöchernen Schneckenhohlraums $6,5 \mathrm{~mm}$, seine Höhe beträgt $3,4 \mathrm{~mm}$ im Durcbschnitt. Sie besitzt wenig mebr als drei Windungen. Diesen Maßen entsprachen auch die von mir untersuchten Objekte.

Bezüglich der Lage in den Dimensionen der Bogengănge kann ebenfalls auf die Angaben Denkers verwiesen werden. Das häutige Labyrinth des Schweines schildert Retzius (40) nur in seiner äusseren Form, wie es durch Herauspräparieren bei Föten gewonnen wurde. Auf die feineren mikroskopischanatomischen und cytologischen Details geht er nicht ein.

Die Wandung des Labyrinths zeigt überall mindestens drei deutliche Schichten, das Epithel als Derivat des ursprünglichen Labyrinthbläschens, die wenig strukturierte Membrana propria und die sie weiter umhüllenden Bindegewebsschichten, in welchen sich die perilymphatischen Raume ausgebildet finden.

Das Bindegewebe des Labyrinths und speziell der perilymphatischen Raume hat eine genauere vergleichend-anatomische Schilderung durch Alexander (1) erfahren, der speziell auch dem hier vorkommenden Pigment seine Aufmerksamkeit zugewendet hat. Meine diesbezüglichen Beobachtungen stimmen mit 
Alexanders Befunden vollkommen überein, so dass ich auf seine Angaben verweisen kann. Bezüglich der nicht weiter differenzierten Epithelauskleidung des Labyrinths möchte ich bemerken, dass sich bei Kali-Bichromat-Formol-Eisessig-Fixierung in seltenen Fallen kleine Diplosomen auffinden lassen, von denen eine ausserst zarte Geissel mit Innenfaden ausgeht. Letztere sehr zarten Gebilde stehen an der Grenze der Sichtbarkeit. Das aussere Diplosomenkorn liegt dicht an der Cuticula.

Unser Hauptinteresse nimmt das Epithel der Nervenendstellen in Anspruch, die Cristae der Ampullen, die Maculae sacculi und Utriculi und das Cortische Organ.

Das Epithel der Cristae (Fig. 26) ist zirka $40 \mu$ hoch. Durcb die Anordnung der Kerne der Sinnes- und Stützzellen in verschiedenen Höhen erscheint es als zweischichtig. Die Sinneszellen oder Haarzellen haben flaschenförmige Gestalt. Sie verjüngen sich von ibrem unteren, bauchigen Anteil bis zur cuticularen Platte, die sie an der freien Oberfläche tragen. Vollkommen gut. fixierte Zellen, wie man sie nur leider seiten zu Gesicht bekommt, zeigen, dass die unter dem Kopf der Zelle gelegene Verjüngungeigentlich nicht existiert und nur durch Schrumpfung bei der Fixierung zustande kommt. Gut erhaltene Zellen füllen den Raum zwischen den sie umgebenden Stützzellen vollkommen aus, ungenügend fixierte zeigen starke Schrumpfung des Protoplasmas, dabei liegt der Kern fast frei, nur von wenig Protoplasma umgeben; von diesem spannen sich nach allen Seiten feine Fädchen aus, welche den zentralen Zellteil mit der zarten Zellmembran verbinden, die in situ fest mit den Stützzellen verkittet zurückbleibt. Ich glaube, dass solche Bilder, die bei gleichzeitiger vorzüglicher Fixierung der Hörhaare, Cupula, der Kerne etc. nicht selten auftreten, den Autoren häufig Anlass zu Missdeutungen gegeben haben. Die grösste Breite der Haarzellen beträgt $10 \mu$ oberhalb der Basis, ihre Lănge $20 \mu$.

Die Kerne sind oval und messen in ihrer grössten Länge $7 \mu$. Die Hörhaare sind zahlreich, verkleben meist an ihrem oberen Ende, ihre Lange ist schwer zu bestimmen (die zentralen sind wohl die lăngsten), übertreffen jedenfalls die Zelle selbst an Länge bedeutend. Die Stützzellen, längliche, zylindrische Elemente mit breitem, pyramidenförmigem Fuss und Kopfteil sind $40 \mu$ lang. Ihr Kern ist dem der Haarzellen recht ahnlich. Sie schrumpfen 
weniger leicht als die Sinneszellen. Die Kopfplatte, ein unregelmässiges Polygon, ist mit den benachbarten Stütz- und Haarzellen durch starke Kittleisten verbunden, die basale Partie, die auf der Limitans inseriert, oft schwer abzugrenzen. Pigment fehlt beim Schwein im Epithel fast gănzlich. Faserige Stützstrukturen sind im Kopfteile der Stützzellen kaum angedeutet und niemals so distinkt zu färben wie in Stützzellen des Cortischen Organs.

Auf der Oberfläche des Epithels finden sich konstant jene eigenartigen, tropfenförmigen Gebilde (Fig. 59 ), die häufig durch ihre Form und die Farbbarkeit mit Eisenalaun an geschrumpfte Kerne erinnern. Eine Anzahl von ihnen entspricht vermutlich veränderten Leukocyten, einzelne vielleicht auch Erythrocyten, die Mehrzahl aber macht durchaus den Eindruck spezifischer Sekrettropfen, die aus den Epithelien stammen. Man trifft auch bei Embryonen schon solche Bildungen in tropfenförmigem Herausquellen aus allen Zellen des Ampullenepithels; spăter bleiben sie auf das Gebiet der Nervenendstellen beschränkt. $O b$ sie zur Cupulabildung in Beziehung stehen, ist nicht recht zu entscheiden, gewiss aber finden wir solche Tröpfchen in Zusammenhang mit der Cupula stehen.

Das Epithel der Maculae entspricht fast volistandig dem der Cristae mit dem Unterschiede, dass die Zellen etwas länger erscheinen und auch das ganze Epithel etwas dicker ist, zirka $54 \mu$.

Die Hörbaare, die etwas kürzer sind als in den Cristae, sind von allen Seiten gegen das Zentrum der Maculae bingeneigt.

Die zylindrischen Epithelien, welche sich neben dem eigentlichen Sinnesepithel befinden und den Übergang zum indifferenten Epithel bilden, das die Bogengänge auskleidet, gliedern sich in eine der Nervenendstelle nahe gelegene Zone sich wenig färbender Epithelien, welche sich konvex nach aussen vorwölben, und eine entfernter gelegene, dunkler sich färbende Zone, deren Begrenzungsfläche konkav gekrümmt erscheint (Fig. 26).

Die die Cristae und Maculae deckende Cupula, die man ja jetzt mit Sicherheit als präformiert ansehen kann, zeigt sich in Form einer feinkörnigen Gallerte, die in einem Abstand von $8-15 \mu \mathrm{dem}$ Epithel aufsitzt. Die Hörhaare ragen in sie hinein. In gewissen Fallen sieht man an ihrer unteren Grenze dünnere oder dickere Fäden, die mit der Oberfläche des Epithels verklebt erscheinen. Bei guter Fixierung erscheint die Substanz der Cupula 
in ihrem dem Epithel zugewendeten Anteil gekämmert, d. h. es scheinen Partien sehr zarter Gallerte von etwas derberén kammerförmig abgeschlossen. Gegen den freien Teil der Cupula hin kann man auch noch eine durch Abwechseln dichterer und hellerer Partien zustande kommende parallele Streifung erkennen.

Die der Cupula der Maculae eingelagerten Otolithen sind sebr verschieden gross, und zwar liegen ganz regelmässig die grössten an der Peripherie der Otolithenmembran. Hier sind sie bis zu $10 \mu$ lang (im Zentrum erreichen sie oft kaum $2 \mu$ ) und ihre Kristallform ist deutlicher ausgeprăgt. Die Kalkkörperchen besitzen eine organische Grundlage, die auch nach der Entkalkung bei günstiger Färbung vollkommen ihre Gestalt erkennen lässt. Die faserige Struktur, die auf Flachschnitten in ziemlich regelmässiger Anordnung die Raume der Otolithenmembran umgibt, in welchen sich die Hörhaare befinden, erinnert stark an fibrinartige Strukturen. $O b$ sie im Leben präformiert ist, war nicht. zu ermitteln.

Der Ductus cochlearis zeigt im wesentlichen alle Teile wie bei allen anderen Säugern.

Die Basilarmembran, die speziell durch ihre Auffassung als Resonanzapparat das physiologisch-anatomische Interesse fesselt, besteht aus drei Lagen (Fig. 5).

Die tympanalwärts gelegene, sogenannte tympanale Belegschicht, als Überbleibsel des die Scala tympani beim Fötus ausfüllenden Gallertgewebes, wird beim erwachsenen Tier aus flachen, häufig spindelförmigen Zellen gebildet, die fast überall in drei, nur selten in einer Schichte angeordnet erscheinen. Es gelingt. nur schwer, zwischen ibnen die Zellgrenzen nachzuweisen, so dass es manchmal fast den Eindruck macht, als habe man es mit einem Syncytium zu tun. Die Längsachsen der Zellen und auch die ihrer länglichen Kerne stehen parallel zur Lăngsrichtung des Schneckenkanals. Die Kerne sind zirka $5 \mu$ lang und 3 « breit. Die tympanale Belegschicht umfasst beim Schwein immer nur ein einziges venöses Blutgefäss (Fig. 5), das vas spirale. Verdoppelungen dieses Gefasses, wie sie bei anderen Tieren vorkommen, sind mir beim Schwein nicht aufgefallen. Die mittlere Lage der Basilarmembran, die eigentlichen Basilarfasern, erscheinen als strukturlose Fasern, die nach den verschiedensten 
Fixierungen in ihrem Verhalten gegen Farbstoffe grosse Übereinstimmungen mit der subepithelialen Membrana limitans zeigen, die wir an anderen Stellen des Labyrinthes finden. Sie zeigen keine feinere Struktur. Ihre Dicke beträgt nach aussen $6-8 \mu$, an den dünnsten Stellen zirka $2 \mu$.

Die Dicke der Basilarisfasern nimmt von unten nach oben in den Windungen merklich $a b$, in den obersten Windungen sind sie nicht über $1,5 \mu$ dick.

Von den Elementen, die auf der Membrana basilaris aufsitzen, ist sie, wie bekannt, durch ein homogenes, strukturloses Häutchen getrennt. Unter diesen lassen sich in seltenen Fallen Kerne nachweisen. Die Fasern der Basilaris sind untereinander durch eine Kittsubstanz verbunden, die sich aber nicht nach Art anderer Kittsubstanzen fürberisch darstellen låsst. Deshalb sind auch auf dem Querschnitt die Fasern der Basilaris schwer abzugrenzen.

Das Corti sche Organ des Schweines bildet einen Spiralwulst von unregelmăssig trapezförmigem Querschnitt. Wie bei anderen Săugern sind seine Gestalt und seine Dimensionen, sowie auch die Grösse der Elemente, die es zusammensetzen, in verschiedenen Windungen ungleich, wie besonders auf Radiärschnitten zutage tritt (Fig. 1-4).

Die folgenden Angaben beziehen sich auf besonders gut fixiertes und schonend entkalktes Material ausgewachsener Mastschweine. Als Kriterien für gute Konservierung galten neben der Erhaltung der ganzen architektonischen Verhalltnisse im allgemeinen, die Konservierung der Haarzellen mit glatten Wandungen und gut abgegrenztem unterem Pol, gute Erhaltung der Nerven, der inneren Phalangen und der Grenzzelle Helds. Die angegebenen Dimensionen sind als Mittelwerte verschiedener Messungen aufzufassen. Der Querschnitt der häutigen Schnecke betrăgt in seiner grössten Dimension, oberhalb der Insertion der Lamina basilaris gemessen:

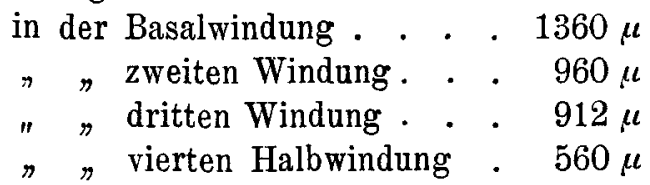

Die Dimensionen der in diesen Windungen ausgespannten Fasern der Membrana basilaris betrugen, von der Habenula perforata zur Ansatzstelle am Ligamentum spirale gemessen: 


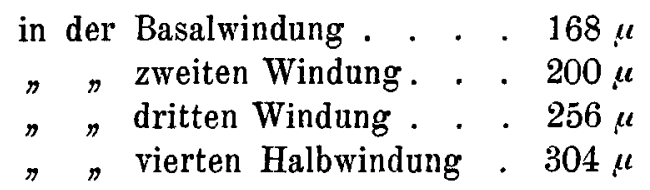

Es sind bei diesen Messungen, die an Radiärschnitten vorgenommen wurden, wie ich ausdrücklich erwähnen möchte, die basalste und oberste Partie des Schneckenkanals aus technischen Gründen nicht berücksichtigt. Damit würde die grösste Breitendimension des hăutigen Schneckenkanals ungleichmässig, um mehr als die Hålfte, von unten nach oben abnehmen, die Membrana basilaris und mit ihr das auf ihr ruhende Cortische Organ um das Doppelte etwa an Breite zunehmen, was hinter den bei andern Säugern beschriebenen Verhăltnissen zurückbleiben würde.

Auf der Membrana basilaris ruhen nun alle jene eigenartigen Gebilde, die durch Differenzierung aus dem gewulsteten Zylinderepithel hervorgehen, das in frühen Embryonalperioden diese Stelle einnimmt. Diese Elemente zeigen, so sehr sie von der gewöhnlichen Form von Epithelien abweichen, doch noch immer gewisse Charaktere von solchen, speziell was die Lage von Kern und Diplosom betrifft.

Es ist eine durch die ganze Tierreihe verbreitete Erscheinung, dass Sinnesorgane und Zentralorgane sich aus Epithelien zylindrischer Form in der Weise entwickeln, dass die einen sich zu Sinneszellen oder Nervenzellen, die zwischen ihnen gelegenen Epithelien sich zu Stützzellen, respektive Gliazellen dadurch entwickeln, dass gewisse fadenartige Stützstrukturen in ihnen sich ausbilden. Das Sängerlabyrinth zeigt diese Erscheinung bloss in höchster Ausbildung, und während wir in Sinnesorganen niederer Tiere nur ganz einfache Stützstrukturen finden, zeigen sich hier jene komplizierten Gebilde, jene Tragbogen, wie sie Held bezeichnet hat, die durch den Zusammenhang der Stützstrukturen der Pfeilerzellen einerseits, der Deitersschen Zellen, Innenphalangen und Grenzzellen anderseits zustande kommen.

Die Pfeilerzellen des Schweines zeigen im allgemeinen dieselbe Struktur, wie sie von R etzius (41), später von J o s e p h (22), in neuester Zeit wieder von Spee (44) und Held (20) beschrieben worden ist; sie zeigen aber einige interessante und cbarakteristische Abweichungen von den Bildern, welche vom 
gleichen Objekt, meistens vom Meerschweinchen, Maus und Katze gegeben wurden. Beide Pfeilerzellen stehen auf der Basalmembran mit ihren unteren Flächen so orientiert, dass eine durch die Mitte ihres Kopfteils gelegte Ebene, die zugleich - gewöhnlich, aber nicht immer - ihre Symmetrieebene darstellt, radiär die Schneckenachse trifft. Die nach innen gewendete Konvexităt der Aussenpfeilerzelle greift in die nach aussen gewendete Konkavităt der Innenpfeilerzelle derart ein, dass sich die Zellen gegenseitig zu stützen scheinen. Schon die ersten Beschreiber dieses Lageverhăltnisses und viele spătere haben offenbar infolge einer ganz grob morphologischen Analogie dieses Bildes mit gewissen Gelenken, z. B. dem Hammer-Amboss-Gelenk, einen in ăhnlicher Weise mit einer geringen Bewegungsmöglichkeit ausgestatteten zellulären Gelenkmechanismus darin vermutet. Erst die neueren Untersuchungsmethoden, die die Zellen besser konservierten und eine genaue Darstellung der Kittsubstanzen erlaubten, haben gezeigt, wie schon $\mathrm{Held}$ ausführlich darlegte, wie irrig diese Vorstellung war, da dieselbeu durch eine gut ausgebildete Kittmasse fest verbunden erscheinen. Die Verbindung der Zellen ist eine so feste und innige, dass bei schlechter Konservierung und verschiedenen mechanischen Insulten alle anderen Bestandteile des Cortischen Organs eher ihre Lagebeziehungen andern oder getrennt werden, als gerade die beiden Pfeilerköpfe. Diese schliessen einen Winkel miteinander ein, der an der Basis der Schnecke spitzer ist, in den distalen Partien des Cortischen Organs der höheren Windungen stumpfer wird.

Die beiden Pfeilerzellen berühren sich aber nicht nur mit ihren Kopfteilen, sondern auch mit dem basalen Anteil (Fig. 5, $6,7)$. Das eigentliche Zellprotoplasma, das als Matrix der faserigen Bildungen, die vorzugsweise ins Auge fallen, in ganz zarter Schicht bis zur streifig cuticularen Deckplatte reichen, den ganzen Pfeiler umhïllt, sitzt basal sehr breit auf der Lamina basilaris auf, so dass sich die fast zum Verschwinden verdünnten Zellkörper in der Mitte des Tunnelraums treffen, was man besonders an zur Basilaris parallelen Schnittserien an den Kittlinien deutlich wahrnehmen kann. Von der Mitte des Tunnels hebt sich das Protoplasma auf dem Radiarschnitt in Form eines sphärischen Dreiecks gegen den mittleren Teil des Pfeilers empor. In der Mitte dieses Dreiecks findet sich der Kern. 
Das Protoplasma erscheint meist homogen. In einigen Făllen aber - vielleicht unter Einfluss fixierender Reagentien - finden sich längs der ganzen Oberfläche der Zelle kleinste, stark lichtbrechende Körnchen. Im Innern dieses Protoplasmas liegen die Faserstrukturen, die den Pfeiler bilden. Es sind, wie es Retzius, Spee, Joseph und Held beschrieben haben, glatte, mit Fuchsin, Eisenhämatoxylin etc. intensiv sich färbende Fasern; sie setzen sich an der Kittmembran oberhalb der Radiärfasern der Membrana basilaris mit einer kleinen, dreieckigen Verdickung fest, bilden zusammenstrebend einen Kegel, ziehen dann näher zusammen, um im Halsteil des Pfeilers eine Strecke weit parallel $z u$ verlaufen. Innerhalb des basalen Faserkegels findet sich ein kleiner, anscheinend homogener, pyramidenförmiger Einschlusskörper, der die Farbe zwar festhält, aber nicht so intensiv gefarbt ist wie die Faser selbst; er scheint hier manchmal frei zu liegen, wie man es bei anderen Tieren, besonders dem Meerschwein, so hăufig sieht, gewöhnlich aber entspringen Fasern aus ihm. $\mathrm{Zu}$ weilen finden sich zwei und mehr basale Einschlusskörper, aus denen dann Fasern hervorgehen. Im Kopfteil weichen die parallelen Fasern des Halses wieder auseinander. Schliesslich biegen sie im Innenpfeiler nach verschiedenen Richtungen ab (Fig. 21), zum Teil ziehen sie gegen die konkave Fläche und setzen daselbst mit kleinen dreieckigen Verbreiterungen sich an die Oberflächenmembran an, welche eine parallele Streifung zeigt. Im Kopfteil des Aussenpfeilers findet sich dann ein zweites, spärlich entwickeltes Fasersystem, das in den Phalangenfortsatz bineinzieht; seine Fasern setzen sich an dem ruderplattchenartigen Ende desselben, das von innen an den Kopf der Haarzellen der zweiten Reihe anstösst, mit dreieckigen Plättchen an. Nach innen $\mathrm{zu}$, gegen den Kopf der inneren Haarzelle hin, stützen sich diese Fasern auf einzelne der Stützfasern des zuerst beschriebenen Systems, mit ihnen einen spitzen Winkel bildend (Fig. 8). Dicht am ausseren Rande der Phalangenplatte finden sich unter der Oberfläche die beim Schwein ausserst kleinen und schwer wahrnehmbaren Diplosomen. Häufig findet sich am Aussenpfeiler, in der Mitte des Halsteils, eine ovale Verdickung des umhüllenden Protoplasmas mit reichlichen Einlagerungen von Pigment und anderen Körnchen. Jene charakteristischen Einschlusskörper, die schon von Walde yer (45) erwähnt wurden und speziell in jhrer 
Ausbildung bei den Nagern von Joseph (22) geschildert wurden, liessen sich beim Schwein nicht finden. Manchmal aber erbalt man den Eindruck, als ob die Seitenteile des Aussenpfeilerkopfs an beiden Seiten durch eine dunkle Masse begrenzt warren. Bei guter Fixierung und gelungener färberischer Differenzierung sieht man dann die seitliche Begrenzung des Aussenpfeilerkopfes in Form einer vielfach unregelmåssig gelochten Platte (Fig. 10), die in ihrem Aussehen mit einer gefensterten Membran (Fig. 21) Ähnlichkeit hat. Diese Membran erscheint nach innen durch Fortsetzung der Pfeilerfasern, die in ihr weiter verlaufen, rippenartig verstärkt. Dieses Verhalten bedingt das eigenartige Bild, das der Aussenpfeilerkopf auf Querschnitten bietet, indem dann ein hellerer innerer Raum von einem dunklen Saum mit nach innen gewendeten Zacken, den Querschnitten der oben erwăhnten Rippen, umsauumt erscheint (Fig. 9).

Der Innenpfeiler ist im wesentlichen ăhnlich gebaut wie der Aussenpfeiler. Er enthalt ebenso reichliche Fasern wie jener und ist wie er im Halsteile auf dem Querschnitte rechteckig. Während aber der Kopf des Aussenpfeilers als Konvexităt sich darstellt, bildet der des Innenpfeilers eine löffelartige Konkavität, welche den Aussenpfeiler überdeckt. Die Fasern ziehen gegen die Konkavităt zu und setzen sich mit dreieckigen Endplättchen an der konkaven Oberfläche an. Ein Teil von ihnen - die in der Mitte gelegenen - ziehen in den nach aussen liegenden Teil des Kopfes, in die flache Platte, welche sich an die Haarzellen der ersten Reihe anlegt und setzen sich hier an (Fig. 21). Sie verleihen dieser Platte bei der Ansicht von oben ein parallelstreifiges Aussehen. Ein kleiner Teil der Fasern, die zu innerst gelegenen, ziehen in einen nach einwärts, zwischen die inneren Haarzellen hineinragenden spitzen Fortsatz, den Held Innenschnabel nennt, um hier, etwas unter dem Niveau der Köpfe der inneren Haarzellen, zwischen ihnen an der Membran zu enden. Auch im Innenpfeiler finden sich beim Schwein keinerlei Einschlusskörper. Am Rande, gegen die Haarzellen hin, zeigen sich die winzigen Diplosomen.

Auf dem Querschnitt zeigt der Innenpfeilerkopf eine eigentümliche, mäanderartige Figur, die durch ineinandergreifende, heller und dunkler gefärbte Substanzportionen gebildet wird (Fig. 11, 12). Durch den Innenschnabel bildet die innere Pfeiler- 
zelle, auch von der Seite her, eine Stütze der inneren Haarzelle; dabei kommen, wie schon $\mathrm{Held}$ hervorgehoben hat, verschiedene Varianten vor, indem der zwischen zwei Haarzellen gelegene Schnabel manchmal von zwei Pfeilerköpfen gebildet wird, ein anderes Mal ein Pfeilerkopf sich an der Bildung zweier Schnäbel beteiligt und so den Kopf der Haarzelle mehr als zur Halfte umfasst (Fig. 9, 11).

Mit grosser Deutlichkeit konnte ich beim Schwein jenes Zellelement sehen, das Held zuerst genauer beschrieben und als "Innenphalange" bezeichnet hat (Fig. o). Es entspricht vollkommen der Beschreibung, die er davon gegeben hat. Der Zellkörper, dem einer zweiten De it er sschen Zelle vergleichbar, nur schmaler, setzt sich nach innen vom Innenpfeiler auf der Membrana basilaris an. Der Mittelteil ist bald schlank und deutlich, bald wieder infolge der Quellung bei der Fixierung breiter und wenig scharf begrenzt. Die Kopfplatte ist sehr klein und schmal und besitzt nicht die typische Form der ausseren Phalangenplatten; der nach innen gewendete Rand ist rund, der nach aussen gewendete mehr spitz und überdeckt, dicht aufliegend dem Innenschnabel der inneren Pfeilerzelle (Fig. 14). Die Kopfplatte enthält Diplosomen. Unter dem Kopfteil sieht man die Andeutung einer Stätzfaserstruktur, sie scheint aber nicht bis in den basalen Teil der Zelle hinabzureichen, der sehr verganglich ist und deshalb einen Maßstab für den Erhaltungszustand des ganzen Prăparates abgibt. In seltenen Fällen finden sich beim Schwein auch zwei Innenphalangenzellen $z$ wischen zwei Haarzellen eingeschaltet (Fig. 13). Der Kern, der mit dem basalen Protoplasma leicht Veränderungen unterliegt, ist chromatinarm, etwas oval, etwa $5 \mu$ lang.

Die innere Haarzelle ist in eigenartiger Weise in den Aufbau des Cortischen Organs eingefügt. Ihr Kopfteil wird einerseits, und zwar nach aussen hin, von den Köpfen der inneren Pfeilerzellen, seitlich von deren Innenschnabel gestützt. An diese schliessen sich die Phalangenzellen an und weiter nach innen Zellelemente, die Held als Grenzzellen bezeichnet (Fig. 14). Schwieriger ist es, die Einfügung des unteren Pols der Haarzelle zu erkennen. Phalangenzelle und Grenzzelle, die diesen hier einschliessen, zeigen nur ausnahmsweise klar ihre Konturen; ein dem Stützkelch der ausseren Deitersschen Zellen homologes Gebilde ist nicht vorbanden (Fig. 5, 21). Nur die in der Grenz- 
zelle gelegenen Fasern, die deren der Haarzelle zugewendete Fläche verstärken, bilden eine sichtbare Stützstruktur für den seitlichen Teil. Ihr unterer Pol scheint also wenigstens in seinem Mittelteil frei über dem schmalen, freien Raum zu liegen, der die aus der Habenula perforata kommenden, marklosen Nerven aufnimmt. Gerade dadurch, dass der untere Teil der Zelle teilweise an andere Elemente grenzt, im übrigen aber frei ist, ist er speziell bei Einwirkung der fixierenden Flüssigkeiten unregelmässigen Verzerrungen ausgesetzt; man erhält deshalb bei vielen Tieren fast niemals tadellose Fixierungsbilder dieser Zellen, so dass manche Forscher von basalen dendritenartigen Verzweigungen sprechen. Beim Schwein macht sich dieser Übelstand wenig bemerkbar.

Die innere Haarzelle (Fig. 5, 21) steht in ihrer Lăngsrichtung in einem spitzen Winkel zur Schneckenachse und zum inneren Pfeiler. Ihr Kopfteil ist etwas grösser als der der ausseren Haarzellen, er ist rundlich und enthălt eine offenbar cuticulare Bildung, den sogenannten Kopfeinschluss, der auf dem Flächenbild unregelmăssige Fortsătze zeigt, die ihn mit dem starken Randreifen verbinden (Fig. 11). Der Kopfeinschluss trăgt die Hörhaare in einem charakteristischen, ganz flachen Bogen angeordnet. Ihre Zahl betrăgt beim Schwein 14-17. Die Hörhaare sind, wie im Gegensatz zu den meisten geläufigen Darstellungen $\mathrm{Held}$ zum erstenmal es richtig dargestellt hat, nicht gleichmässig dick, sondern besitzen an der Basis einen kaum sichtbaren, feinen Teil, mit dem sie in die Zelle eingefügt sind; auf diesen folgt ein dickerer, stark färbbarer Abschnitt, dann ein längeres, weniger färbbares Stück, das mit einer kleinen, keulenartigen Verdickung endet (Fig. 25). Die Haare stehen, nach innen geneigt, in derselben Richtung wie die ausseren Pfeiler, so dass man auf Schnitten in einer gewissen Richtung sehr häufig die ausseren Pfeiler der Lảnge nach getroffen sieht und in ihrer Verlängerung einen Abschnitt des Innenpfeilerkopfes und der inneren Haarzelle mit den der Länge nach getroffenen Hörhaaren (Fig. 25).

Die Kopfplatte enthält in einem der vom Einschlusskörper freigelassenen, helleren Răume ein centrosomartiges Körnchen (Fig. 11). Der Halsteil der inneren Haarzelle verdickt sich 
langsam gegen den basalen Teil zu, um wenig oberhalb des Kerns die grösste Breite zu erreichen. Das Protoplasma erscheint gewöhnlich ziemlich homogen; kopfwärts, bezw. basal gelegene Portionen des Protoplasmas, die dem Hensenschen und dem Retziusschen Körper entsprechen würden, sind nicht mit Sicherheit zu differenzieren. Dagegen findet man gelegentlich auch in Făllen, wo eine sehr gute Konservierung vorzuliegen scheint, d. h. die Zelle ohne jede Schrumpfung und Vakuolisierung mit vollkommen runder Basis von einer ganz glatt gespannten Oberflachenmembran umgeben erscheint, im Protoplasma ein mit Eisenhămatoxylin farbbares, feinmaschiges Gitterwerk, das, im Farbenton mit ihnen übereinstimmend, sich direkt in die an der Basis mit kleinen Knöpfen ansetzenden, marklosen Fäserchen fortsetzt und wahrscheinlich, wenigstens teilweise, dem mit der Silbermethode darstellbaren Neurofibrillengitter im Zellkörper entspricht (Fig. 21). Der Kern ist kugelrund, wenig strukturiert, und enthält wenige Körnchen und einen kleinen Nucleolus. Bei bester Fixierung findet man leicht auch auf dünnen Schnitten mehrere Nervenfäserchen, die mit leicht welligem Verlauf an die Zellbasis herantreten. Hier zeigen sie deutliche, kleine Knöpfchen, die aber beim Schwein nur wenige protoplasmatische Körnchen mitzuführen scheinen, so dass es mir nicht gelang, ein typisches Neurosomenbild im Sinne von Held hier zu sehen. Die Verdickungen zeigen wahrscheinlich die Stelle an, wo die Perifibrillärsubstanz des Achsenzylinders aufhört und die Fibrillen des Nerven in diejenigen des Sinneszellkörpers übergehen (Fig. 5, 21).

Nach einwarts, gegen den Sulcus spiralis hin, wird die innere Haarzelle durch das Element, das Held "Grenzzelle" genannt hat, gestützt, bezw, teilweise überdeckt. Wie Held selbst bemerkt, hat er bei den von ihm untersuchten Objekten Maus, Meerschwein, Hund, Katze, eigentliche Stützfasern darin nicht differenzieren können, hat es aber doch ganz richtig als Stützelement aufgefasst. Diese Zelle, die im Bau an die Elemente erinnert, welche nach aussen den Abschluss des Cortischen Organs bilden, ăhnelt stark der innersten Reihe der Hen se n schen Zellen. Ihre meist rechteckige Kopfplatte schliesst sich an die Kittleiste der inneren Haarzelle und Innenphalangen an, nach innen an die flachkubischen Zellen des Sulcus spiralis. In ihrem Mittelteil ist die Zelle flach konkav-konvex, so dass ihre Konkavitat die 
Wölbung der inneren Haarzelle aufnimmt. Basal sitzt sie, sich verbreiternd, innerhalb der Habenula perforata auf (Fig. 5, 21). Eine die Basis der inneren Haarzelle stützende Struktur ist nicht zu sehen, dagegen gelang es mir, Stützfasern unter der nach aussen gewendeten, konkaven Zellmembran nachzuweisen. Diese setzen sich in der Zahl von drei an die haarzellenwärts gelegene Kittleiste an, zeigen im Verlauf nach unten Verbindungen untereinander (Fig. 14), in der Basis der Zelle kann man sie schwer unterscheiden. Bei der Form und Lagerung der Grenzzelle ist es schwer, die Faser zu sehen; am besten gelingt es auf Schnitten, die der Reisnerschen Membran parallel gerichtet sind. Wie bei der inneren Phalangenzelle ist beim Schwein auch an der Grenzzelle bei guter Fixierung die Membran erhalten und das Bild der sog. Körner W a lde y ers (45) kommt hier nicht so leicht zustande wie bei anderen Tieren.

An die Grenzzelle schliessen, sich abstufend, die Zellen des Ductus spiralis an, die, in Form unregelmässiger Polygone aneinanderstossend, den Hohlraum auskleiden. Sie haben ein undifferenziertes, homogenes, leicht vakuolisierbares Protoplasma. In einer Ecke der oberflächlichen Platte findet man unschwer das Diplosom.

Die Deitersschen Zellen sind ein vielumstrittenes Objekt. Die Kenntnis ihrer eigentlichen Form ist erst eine Errungenschaft der neueren Forschung und der verfeinerten Untersuchungsmethodik. Dadurch, dass es nicht möglich ist, durch sie in irgend einer Richtung eine Symmetrie-Ebene zu legen, unterscheiden sie sich von den meisten übrigen Zellen der Wirbeltiere. Die Vorstellungen, die sich die verschiedenen Untersucher, von Deiters (9) angefangen, über ihre Form und ihr Verhältnis zu den Sinneszellen gemacht haben, waren sehr wechselnde, und erst die Vergleichung ihrer Form bei vielen Săugern und die Untersuchung mit den verschiedensten Methoden konnte es aufklären, wie so entgegengesetzte Meinungen sich bilden konnten. Dass die früher geläufige Vorstellung: dass die Deitersschen Zellen und die Haarzellen Zwillingszellen seien, oder dass die Haarzellen neben den Deitersschen Zellen auf der Lamina basilaris aufstünden, nicht mehr $\mathrm{zu}$ Recht besteht, ist den Forschungen von Retzius (40), Spee (44) und Katz (25) zu danken. Ihre eigentliche Form und ihre Struktur ist aber in voll- 
kommen richtiger Weise zuerst von $\mathrm{Hel} d(20)$ aufgeklärt worden. Ich möchte hier gleich bemerken, dass die Angaben $\mathrm{Helds}$, die er in seiner ausgezeichneten Arbeit bezüglich der Stützsubstanz, vor allem bei Meerschwein und Maus, macht, bei diesen Objekten sich bis ins kleinste Detail wiederfinden liessen, und dass auch beim Schwein, beim Pferd, den Wiederkäuern, bei Fledermäusen und Insektenfressern die Verhältnisse ganz ähnliche sind, mit einigen charakteristischen Eigentümlichkeiten, die zunächst, speziell vom Schwein, hier geschildert werden sollen.

Die Deiterssche Zelle sitzt mit ihrer Basis in der Form eines unregelmasssigen Polygons auf der oberen Grenzschicht der Membrana basilaris. Von hier erhebt sich der untere Teil der Zelle in einem spitzen Winkel, der der gleiche ist, den die äusseren Haarzellen mit der Schneckenachse einschliessen (Fig. 5, 15-19). Die Zelle ist im unteren Teil, dadurch, dass sie mit den Flächen der Nachbarzellen zusammenstösst, prismatisch. Etwa in halber Höhe der Zelle, dicht unterhalb des unteren Poles der Haarzellen, teilt sich das Protoplasma in zwei ungleiche Fortsătze. Der eine, breite Fortsatz wurde von Held als „unterer Kopf ${ }^{\prime \prime}$ bezeichnet. Fr umschliesst den unteren Haarzellenpol und bildet für ihn eine Stütze, der andere Fortsatz läuft schmal zu und liefert ein eigenartiges Gebilde, den oberen Kopf der Deitersschen Zelle oder den Phalangenfortsatz, einen langen, schmalen, $1-2 \mu$ breiten Protoplasmafaden, der schliesslich, mit der Phalangenplatte endend, zwischen dem Kopfe der Haarzellen sich einfügt (Fig. 15). Das Protoplasma der Zelle erscheint wenig strukturiert, zeigt hăufig Vacuolen, auch ist die zarte Zellmembran leicht Faltungen unterworfen. Der wenig strukturierte, im unteren Drittel gelegene, runde, etwa $5 \mu$ breite Zellkern zeigt ein kleines Kernkörperchen. Das Protoplasma umschliesst höchst eigentümliche Differenzierungen, fädige Bildungen, die durch ihre Form und Anordnung, sowie durch die optische und färberische Übereinstimmung mit den Fasern der Pfeilerzellen ohne weiteres den Eindruck von Stützfibrillen machen. Diese Faden - es ist ein ganzes Bündel - entspringen in der Mitte der Zellbasis, oft scheinbar miteinander verschmolzen, mit einem kleinen, kegelförmigen Fuss (Fig. 17, 18); sie durchziehen die Zelle, ein wenig zur Lăngsrichtung geneigt, und băufig etwas gewunden. Der basale Teil des Faserbündels, der sog. „Retziussche 
Faden", teilt sich nun unterbalb der Stelle, an der das Protoplasma sich in die beiden Fortsătze spaltet; ein Teil der Fasern zieht in den unteren Kopf der Zelle und bildet hier, sich verbreiternd, eine eigenartige Figur, den sog. Stützkelch (Fig. 15, 16).

Vier bis fünf unterscheidbare Fasern weichen nămlich mit dreieckigen Verbreiterungen auseinander und bilden, bald mit einem glatten Rand nach oben abschliessend, bald durch Querbrücken miteinander verbunden (Fig. 23), einen zu drei Viertel die Basis der ausseren Haarzelle umschliessenden Kelch, der, mit einem Viertel nach innen zu, dort, wo von den Spiralnervenzügen die Fäserchen an die Basis der Haarzelle herantreten, offen bleibt. Der Kelch scheint die deutliche Membran der Haarzellen ganz dicht zu umschliessen, an günstigen Stellen aber siebt man, dass die Kelchfasern nicht die eigentliche Oberflăche der Deitersschen Zelle erreichen, sondern von allen Seiten von einem äusserst feinen Protoplasmaüberzug überdeckt sind. Der zweite Teil des von der Basis entspringenden Faserbündels zieht in den oberen Fortsatz der Zelle zur Phalange. Hier sind die Fasern meist so dicht aneinander gelagert, dass sie zumeist eine optische Einheit bilden. Erst im oberen Teil, wo eine pyramidenförmige Verbreitung des Protoplasmas sich an die längsovale oder biskuitförmige Phalangenplatte anschliesst, weichen sie meist in der Zahl von drei auseinander und setzen sich an den Randreifen der Platte, wie alle Stützfasern, mit dreieckigen Verbreiterungen an (Fig. 18, 19). Die eben beschriebene Anordnung der Stützsubstanz ist typisch, besonders für die erste und die Halfte der zweiten Windung beim Schwein. Variationen ergeben sich insofern, als die Faserportion des Phalangenfortsatzes bald mehr basal (Fig. 16), bald mehr kopfwarts sich von den Kelchfasern trennt, manchmal auch an der Bildung des Kelches sich beteiligt, so dass dann der Phalangenfortsatz seitlich aus dem Kelchrand zu entspringen scheint (Fig. 15). Zuweilen, wie dies schon He Id bemerkte, liefert eine Deiterssche Zelle $z$ wei Kelche (Fig. 17), seltener beteiligen sich beim Schwein zwei Zellen an der Bildung eines gemeinsamen Kelches. Die Einfügung des Phalangenfortsatzes in das Mosaik der Membrana reticularis (Fig. 20) erfolgt derart, dass er, von seiner Zelle entspringend, nicht neben die von dem zugehörigen Kelch gestützte Haarzelle sich einfügt, sondern häufig mit deutlichen, winkeligen Biegungen an mehreren nächstgelegenen Zellen (zum Unterschied Archiv f. mikrosk. Anat. Bd. 70. 
von anderen Tieren sind es meist zwei bis drei) vorüberzieht und dann erst sich zur Platte aufwarts wendet.

Während in der Basalwindung die zu äusserst gelegene Reihe der Deitersschen Zellen nur wenig in ihrer Gestalt von den inneren abweicht, ist in den höheren Windungen diese Zelle, wie es $\mathrm{Held}$ beim Meerschwein und Hund geschildert hat, zu einem „Tragbogen " ausgebildet, indem ihr oberer dünner Fortsatz bogenförmig sich krümmt und dadurch zwischen ihr und der äussersten Haarzelle ein grösserer Hohlraum zustande kommt. Dabei ist ihr Stützfasersystem anders ausgebildet, als das der übrigen Deitersschen Zellen. So stark abweichende Formen, wie sie Held vom Meerschwein abbildet, zeigen diese Zellen beim Schwein allerdings nicht, immerhin eine auch etwas grössere Anzahl von auseinander weichenden Stützfasern und einen runden Phalangenfortsatz, an dessen Randreif sich fünf bis sechs Fasern in Blumenkelchform ansetzen (Fig. 19).

In ihrem gesamten Aufbau bilden die Pfeilerzellen mit den Deitersschen Zellen und den Innenphalangen und Grenzzellen jenes bogenförmige Auf hängungssystem für die eigentlichen Sinneselemente, wie dies in ausgezeichneter Weise Held dargestellt hat. Dabei ist $z u$ bemerken, dass die Haarzellen nicht nur aufgehängt, bei ihrer besonders festen Verkittung mit den Phalangenfortsătzen einerseits, mit den Stützkelchen andererseits, sondern als frei ausgespannt betrachtet werden müssen und vor gegenseitiger Berührung; sowie Druck und Zug in der Längsrichtung besonders geschützt erscheinen.

Die äusseren Haarzellen sind beim Schwein, im Vergleich zu andern Säugern, in allen Dimensionen ziemlich stark entwickelt, ihre Einfügung ins Cortische Organ ist sehr kompliziert, man muss von Authängung oder Ausspannung sprechen. Der Kopf der Zelle sitzt in einem zur Schneckenachse offenen spitzen Winkel, in einem Rahmen, der, wie bekannt, bei den Haarzellen erster Reihe vom ruderblattartigen Phalangenfortsatz der äusseren Pfeilerzelle nach innen, von den anderen Seiten aber (bei der zweiten und dritten Reihe von allen Seiten) von den Phalangenplatten und ihrem Kittleistensystem gebildet wird. Diese Befestigung ist, wenn man den schmalen Raum in betracht zieht, an dem sie erfolgt, eine äusserst feste zu nennen. Mit ihrer Basis 
reicht die Zelle, die bei guter Konservierung vollkommen zylindrisch und mit einer recht widerstandsfahigen, glasigen, prallgespannten und vollkommen glatten Zellmembran versehen ist, bis in den oben beschriebenen Kelch der Deitersschen Zelle (Fig. 16), in den höheren Windungen bis an das den Kelch vertretende Stützpolster (Fig. 18, 19). Hier ist die Zelle mit der Substanz der Deitersschen Zelle auch verkittet und zwar so fest, dass sie sich auch in Zupfpraparaten kaum jemals von ihr trennt und dadurch den Anlass zur Vorstellung von Zwillingszellen gegeben hat. Es ist wohl der einzige bekannte Fall, in dem eine Zelle, an beiden Polen befestigt, sonst frei in der Körperflüssigkeit aufgehangt erscheint. Dieser Umstand ist bei der theoretischen Verwertung der anatomischen Verhaltnisse im Cortischen Organ bisher viel $\mathrm{zu} \cdot$ wenig beachtet worden.

Der Kopf der Haarzelle wird von einer cuticularen runden Platte gebildet, welche mit etwas verdickten Ründern über die zylindrische Seitenfläche der Zelle hinabgreift und ihr wie ein Deckel aufsitzt, ringsum durch Kittleisten mit den oben erwähnten Phalangenfortsătzen verbunden. In der Mitte der Platte befindet sich der Kopfeinschluss, ein meist homogen und dunkel sich färbender Körper von vielleicht cuticulärer Provenienz (Fig. 21, 22). Er besitzt auf dem optischen Querschnitt die Form eines gleichschenkeligen Trapezes, mit der långeren Kante gegen die freie Flăche hin gewendet. Bei Betrachtung von der Fläche her gehen auch bei bester Konservierung ganz konstant radiäre, gefürbte Fortsätze vom Einschlusskörper zum Randreifen der Kopfplatte. Zwischen letzteren bleiben hellere Răume frei; in einem dieser Raume findet sich - wie Spee (44) und Held (20) auch bei ihren Objekten schon es fanden - ein einfaches Korn, wahrscheinlich ein Zentralkörper. Weitere Zentralkörper im Protoplasma der Zelle oder dem Einschlusskörper zu differenzieren, war mir nicht möglich. Auf dem Einschlusskörper inserieren, in einem Hyperbelbogen angeordnet, die Hörhaare, 14, 16-18 an der Zahl. Es ist nicht ganz leicht, sie zu zählen, da kaum jemals alle Haare oder deren Querschnitte bei genügender Vergrösserung in eine optische Linie zu liegen kommen. Die Hörhaare, etwa $1 / 5 \mu$ dick und durch noch schmälere Zwischenräume getrennt, entsprechen im Bau vollkommen der Beschreibung Helds. Ihr unteres, frei auslaufendes Ende ist so spitz, dass man auch mit den besten 
Objektiven seine eigentliche Insertion in die Zelle kaum wahrnehmen kann.

Diese Befestigungsweise bringt es mit sich, dass schon ein. geringes Schrumpfen des Celloidins im Schnitt oft die Haare von der Zelle losreisst. Untereinander sind diese Haare, auch desselben Zellelements, nicht gleich lang, zum Unterschied von denen der inneren Haarzelle. Die in der Mitte des Bogens stehenden sind am längsten. Der basale, dickere Teil der Haare hält lange die Farbe zurück, der periphere, schmale weniger. Dieser Unterschied ist bei Osmiumfixierung nicht ausgeprägt. Die Haare stehen gegen die Lăngsachse der Schnecke etwas mehr geneigt als die Achse der Zelle selbst. Das Protoplasma der Haarzelle beansprucht besonderes Interesse. Da alle Wahrscheinlichkeit dafür spricht, dass wir hier den Ort zu suchen haben, wo die Schallenergie selbst, oder nachdem sie irgendwie in mechanischeEnergie umgewandelt wurde, jenen uns noch unbekannten Vorgang veranlasst, den wir als Nervenerregung bezeichnen, erscheint. hier auch das kleinste morphologische Detail, wenn es nur konstant ist, wichtig.

Die meisten bisherigen Untersucher haben das Protoplasma der Haarzelle als homogen geschildert, speziell hat Retzius und in neuester Zeit Held dies auch bei Besprechung des frischen Objekts betont. Tatsächlich erscheint auch bei den meisten. Fixierungen das Protoplasma der Haarzelle homogen, nur manchmal finden sich einzelne Körnchen, die die Farbe etwas stärker zurückhalten. In einzelnen, besonders günstigen Fällen aber, nach Fixierung mit Kalium-Bichromat-Formol-Eisessig, zeigt das Protoplasma eine fein fibrilläre Struktur; einzelne deutliche grössere Maschen werden von feinsten Fibrillen im ganzen Zellkörper gebildet, es ziehen solche am Kern vorbei; in besonderer Mächtigkeit und eng aneinander gereiht findet man sie im untersten Teil der Zelle, so dass bei partieller Färbung dieses Zellabschnittesjener Komplex hervortritt, der dem an diesem Ort beschriebenen Retzi us schen Körper entspricht (Fig. 22).

Es gelang mir leider nicht, bei erwachsenen Tieren und speziell beim Schwein mit der Methode Cajals jene den ganzen Körper der Haarzelle durchsetzenden Gitterwerke darzustellen, die ich bei Embryonen und wenige Tage alten Nagern - wie weiter unten geschildert werden soll - als ganz konstant und 
mit den Neurofibrillen der Achsenzylinder in direkter Verbindung, nachweisen konnte. Es sind leider für die erwachsenen Tiere, wie in der technischen Einleitung gesehildert wurde, die bisherigen Methoden nicht ausreichend.

Dass aber konstante Strukturen wohl vorhanden sein können, wenn auch viele gute Fixierungs- und Färbungsmethoden sie niemals zeigen, dafür ist der sogenannte $\mathrm{Hensensche} \mathrm{Körper} \mathrm{im}$ oberen Teil der Haarzelle ein ausgezeichnetes Beispiel. Wahrend die Kalium-Bichromat-Eisessig-Methode davon nichts zeigt, Sublimatfixierungen nur selten ihn zur Darstellung bringen, ist er leicht und konstant in allen ausserern Haarzellen nach Fixierung und Entkalkung mit Trichlormilchsäure und Trichloressigsăure nachzuweisen. Es findet sich nämlich dann unterhalb der Kopfplatte und manchmal anscheinend sie erreichend ein Paket von ziemlich dicken, ganz intensiv gefärbten, spiralig ineinander gewundenen und geschlängelten Fäden, zwischen denen auch manchmal Querbrücken auffallen. Sie lassen sich bis gegen den Kern, nicht aber unterhalb desselben verfolgen (Fig. 24). In Silberpräparaten finden wir neben den Neurofibrillen, die schwarz gefärbt sind wie ich schon in einer früheren Publikation anführte - an der Stelle des Hensenschen Körpers ein aus braunen, untereinander verbundenen, feinkörnigen Fäden zusammengesetztes Gebilde, welches vollkommen denjenigen Strukturen entspricht, die hier andere Zylinderzellen zeigen. Dieses Gebilde, das übrigens beim Embryo und den jungen Tieren sämtlichen Zellen des Canalis cochlearis, nach dessen Differenzierung speziell den Zellen des grossen und kleinen Epithelwulstes angehörig erscheint, wurde in anderen Zylinderzellen für eine Ausfüllung jenes von $\mathrm{Holm}$ gren beschriebenen Kanälchensystems von Cajal und Holmg r e n selbst erklärt, das letzterer als Trophos pongium bezeichnet hat. Es dürfte somit dieser Bestandteil der Zelle - der Hensensche Körper - als spezielle Umwandlung oder als ein Überbleibsel jenes allgemeinen Zellorgans anzusehen sein, das sich eben in den ausseren Haarzellen über die Embryonalperiode hinaus sichtbar erhalt.

Jene typischen Vakuolen, von denen Held in seiner Arbeit Erwähnung tut, konnte ich in den Haarzellen des Schweins bei guter Fixierung niemals finden.

Wie $\mathrm{Held}$ speziell in seiner neuesten Publikation darauf 
wieder hingewiesen, zeigen die Haarzellen und ihre Haare in den verschiedenen Windungen verschiedene Dimensionen und zwar in der Art, dass von der Basis bis zur Spitze der Schnecke die Längen der Haarzellen stark (Fig. 2-4), die ibrer Haare in geringerem Maße zunehmen. Beim Schwein ergaben Messungen folgende Verhaltnisse:

Die aussere Haarzelle der Basalwindung besitzt eine Länge von 21 p

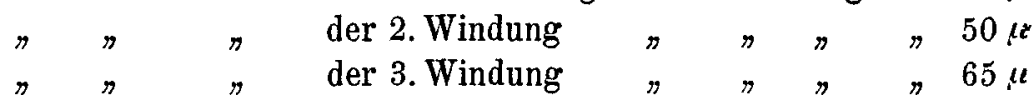

Der im Kopfe der Haarzelle gelegene Körper, die „Kopfeinlage", nimmt von unten nach oben an Grösse ab. So beträgt. deren Breite an der Basis $6 \mu$, in der 3. Windung bloss $3 \mu$.

Was die Hörhaare betrifft, so ist ihre Lange beim Schweir bei der inneren Haarzelle, bei der 1., 2., 3. auss. Haarzelle Basalwindung $\quad 3 \mu \quad 2 \mu 2 \mu 2 \mu$ 2. Windung $7 \mu \quad 6,5 \mu 8 \mu 8 \mu$ 3. Windung $9 \mu \quad 7 \mu 8 \mu 8 \mu$

Ob man auf Grund dieser Differenzen den Hörhaaren jene Bedeutung eines abgestimmten Resonanzapparates zumessen kann, wie es Held andeutet, muss vorlăufig dahingestellt bleiben.

In der obersten Windung findet sich manchmal eine vierte Haarzelle. Gegen das Ende der Schnecke hin treten in den Reihen der Haarzellen Lücken und Unregelmässigkeiten auf, so dass oft nur zwei Reihen von Haarzellen zu finden sind.

An die Haarzellen und die ausseren Deitersschen Zeller schliessen sich die Hensenschen Zellen an. Es sind fünf bis sechs Reihen prismatischer Elemente, welche sich gegenseitig zu stützen scheinen und fest miteinander der ganzen Lănge nach verkittet erscheinen. Die Länge der Zellen nimmt von innen nach aussen ab. In der Gegend der zu innerst gelegenen Zelle liegt die höchste Erhebung des Wulstes, welchen das Cortische Organ bildet. Die der Stria zugewendete Fläche der Zellen ist. etwas konvex, die nach innen gerichtete konkav. Die der $R$ eisnerschen Membran zugewendete Flăche ist nach innen aufwärts dachförmig geneigt; sie bildet ein unregelmăssiges Polygon. Die basale Fläche steht auf der oberen Grenzschicht der M. basilaris auf. An der oberen Fläche finden wir starke Kittleisten entwickelt. Dicht unter der Oberfläche liegen die kleinen, punktförmigen Diplosomen, von einer kleinen, nur selten deutlich sicht- 
baren Area umgeben. In den am weitesten nach innen gelegenen Hensenschen Zellen finden sich manchmal deutliche Stützfaserbildungen von grosser Feinheit, welche fast die ganze Zelle durchziehen. Sie setzen sich an den schwach entwickelten Randstreifen der Deckplatte an. Fettröpfchen, wie sie z. B. die Nager so häufig in diesen Zellen zeigen, konnte ich nie auffinden, auch nicht jenen eigenartigen, gestrichelten und an den Stäbchensaum von Darmepithelien erinnernden Saum, den ich zuweilen bei Fledermäusen beobachtete.

Nach aussen zu gehen die Hensenschen Zellen in die Claudiusschen Zellen über, welche niedrigzylindrische Epithelzellen mit homogenem Protoplasma sind, die keine Besonderheiten aufweisen. Sie gehen langsam in die Epithelien über, die den Sulcus spiralis externus auskleiden.

Zwischen den Hensenschen und Claudiusschen Zellen finden wir besonders in der Basalwindung eine Reihe (drei bis sechs) eigenartige Zellelemente in der Weise eingeschoben, dass sie in Form eines mit der Spitze nach oben gerichteten Keiles auf der Membrana basilaris aufsitzend, die Hensenschen und Cla udiusschen Zellen auseinanderdrängen (Fig. 6). Es sind kleine Elemente, die oben dicht aneinander gedrängt erscheinen, während ihre basalen Anteile breiter sind. Ihr Protoplasma unterscheidet sich sowohl von dem der $\mathrm{Hensenschen} \mathrm{als} \mathrm{auch} \mathrm{von}$ dem der Claudiusschen Zellen auffallend dadurch, dass es sich mit allen Farbstoffen besonders intensiv tingiert. Es zeigt ausser feinsten Körnchen keinerlei Besonderheiten.

$O b$ diese Zellen etwa für im Lauf des Lebens zugrunde gehende Elemente, die in ihrer Năhe liegen, ein Ersatzmaterial darstellen, oder Zellen sind, die durch stärkere Entwicklung der Nachbarn quasi in ein kleineres, embryonales Stadium zurückgedrängt wurden, ist fraglich.

\section{Stria vascularis.}

Die Stria vascularis bietet beim Schwein wenig Besonderheit. Zum Studium dieser Gegend eigneten sich besonders Präparate, die in Perenyischer Flüssigkeit fixiert und mit Eisenhămatoxylin und Rubin gefärbt waren. Es lassen sich in ihnen die feinen Bindegewebsfibrillen besonders genau verfolgen. 
Das Epithel, das mehrere Lagen aufweist, zeigt zwei Typen von Zellen; die tiefer gelegenen Zellen sind etwas mehr zylinderförmig und zeigen an der Basis kleine Fortsätze, die oberste Schichte hingegen ist besonders flach; die Höhe der Zelle beträgt oft kaum $1 \mu$. Die Blutgefässe, sehr weite Kapillaren, finden sich, wie bekannt, allseitig von Epithelzellen umschlossen. Man trifft sogar bis zu $20 \mu$ dicke Venen, die vom Epithel umschlossen werden. Jene eigenartig langen Epithelien, deren weitverzweigte basale Fortsätze tief ins Bindegewebe sich erstrecken, und die von Prenant (39) und Retzius (41) bei verschiedenen Tieren des näheren geschildert wurden, sind beim Schwein nur selten anzutreffen. Sowohl im Epithel, als besonders im darunter liegenden Bindegewebe findet sich reichlich Pigment, in letzterem auch ganze dichtgedrăngte Gruppen von Pigmentzellen.

\section{Reisnersche Membran.}

Die Reisnersche Membran des Schweines ist, wie bei den meisten Säugern, sehr einfach gebaut. Ihre flachen, grossen Epithelien enthalten Pigmentkörnchen in geringer Zahl, etwas Fett und häufig Vakuolen. Gefässe in der vestibularen Belegschichte, die wesentlich den Charakter eines Endothels zeigt, sind nur selten in den oberen Windungen; in den unteren fehlen sie gänzlich. Elastische Fasern finden sich vereinzelt.

\section{Membrana tectoria.}

Die Membrana tectoria, die in Beziehung auf Genese, Lage und Funktion noch immer in vieler Hinsicht rätselhaft ist, zeigt sich beim Schwein in recht verschiedener Gestalt.

Sie ist auf dem Radiärschnitt bald schmal und lang ausgezogen, wenn sie auf dem Cortischen Organ aufliegt, bald aber wieder zeigt sie eine sehr erhebliche Breite und Wölbung und ist dabei nur wenig von der Oberfläche des Cortischen Organs abgehoben. Leider war ich bisher trotz vieler Bemühungen nicht imstande, sie in situ am überlebenden Objekt zu sehen. Immerhin habe ich aus den Bildern, die sich bei gelungener Fixierung in situ durch Injektion ergeben, die Überzeugung gewonnen, dass die Membran intra vitam nur wenig von den Haaren der Haarzellen abgehoben sein kann. Alle jene Abhebungen und Verkrümmungen der Membran, die auch die vollkommenste Technik 
bisher nicht vermeiden kann, müssen als Verlagerungen durch Schrumpfung bezw. Quellung der versehiedenen Teile der Membran aufgefasst werden.

Die Membran (Fig. 50) besteht aus langen, äusserst zarten, $0,25 \mu$ dicken Fasern, welche durch eine offenbar gallertartige Substanz verbunden sind. Es scheint, dass gerade letztere Substanz es ist, aus deren Veränderungen durch die Fixierung die schliessliche Gestalt der konservierten Membran zustande kommt. Die Fasern ziehen immer fast parallel, aber nicht vollkommen radiär zum freien Rande der Membran, wo sie oft auseinanderweichen. Abgesehen von ihrer Anheftungsstelle am Limbus spiralis ist die Membran ringsum von einem deutlich entwickelten Oberflächenhäutchen begrenzt. Dieses enthălt ein besonderes System von Fasern, in. dem zarte, kurze, radiäre Fäserchen mit gröberen, bis zu $2 \mu$ dicken, spiral verlaufenden, zu einem grobmaschigen Netz oder Balkenwerk verbunden sind. Die Färbbarkeit der Zwischensubstanz ist ăusserst gering, die der Fasern etwas grösser. Speziell die dickeren, längsverlaufenden Fasern färben sich mit den meisten Farbstoffen stärker und erscheinen auf dem Querschnitt deutlich als schwarze Punkte. Am meisten treten die Fasern oberhalb des freien Randes der Membran hervor, unterhalb ist es hauptsăchlich eine besonders dicke Faser, wie sie auch bei anderen Säugern schon gefunden wurde. Dagegen fehlt beim Schwein jene stark färbbare Faser, deren Querschnitt bei anderen Tieren am freien Rande selbst gelegen ist.

Was die Beziehungen der Membrana tectoria zu den Gebilden des Canalis cochlearis betrifft, so sind bekanntlich von den Antoren die verschiedensten Meinungen geäussert worden. Bald sollte die Deckmembran im embryonalen Stadium von allen, bald nur von gewissen Zellen des Canalis cochlearis gebildet oder abgeschieden werden. Sie sollte bald mit allen Elementen des C o r ti schen Organs, bald mit den Phalangen, bald nur mit den Haarzellen in Zusammenhang stehen oder auch nur mit letzteren in Berührung sein. Man findet beim Schwein auch bei guter Fixierung die Membrana tectoria den ausseren Haarzellen und den dazwischen liegenden Stützelementen, sowie auch noch den $\mathrm{H}$ e $\mathrm{n}$ s e $\mathrm{n}$ schen Zellen aufliegend. Es sind aber in solchen Fällen immer die Elemente des Cortischen Organs mehr minder stark verzerrt, sodass ich es wohl für berechtigt halten möchte, diese Lage als 
ein Kunstprodukt durch die Fixierung anzusehen. Immerhin ist es unwahrscheinlich, dass die Membran bei der Fixierung sich in radiärer Richtung ausdehnen könnte, und man muss wohl annehmen, dass auch intra vitam dieselbe über die $\mathrm{H}$ en s e $\mathrm{n}$ schen Zellen hinausragt, was ich betonen möchte, da die meisten Lehrbücher den Rand dèr Membran oberhalb der letzten Phalange zeigen. Wiederholt liess sich beobachten, dass (es handelte sich dabei um ausgewachsene Tiere) die Hörhaare aller drei äusseren Haarzellen durch feine, 4 bis $5 \mu$ lange Fäserchen mit den Elementen der unteren Grenzschicht der Membrana tectoria verbunden waren. In solchen Fallen erschien das durch Eisenhämatoxylin dunkel gefärbte Haar bald verklebt, bald umgeben mit der Substanz des durch Rubin intensiv rot gefarbten Fadchens. Auch trifft man nicht selten solche anscheinend durch Zug abgerissene Fadchen an der Membrana tectoria über den Haarzellen hängen. Diese Bilder (Verbindungen mit anderen Elementen als den Haarzellen kommen nicht vor) stimmen mit den diesbezüglichen Angaben verschiedener Autoren, speziell Rickenbachers (42), überein und sprechen entschieden für das Bestehen von Zusammenhängen während der Entwicklung, die dann manchmal erhalten blieben. Die verbindenden Fadchen gehen unvermittelt in die Substanz der unteren Grenzschicht der Membrana tectoria über und scheinen dieser anzugebören. Die Membran reicht immer mit mehr als einem Drittel ihrer Breite über die Anheftungsstelle der Fădchen hinaus (Fig. 48). Ich lege auf solche Bilder deshalb Wert, da ich in einer grösseren Anzahl von Fallen dieses Verhalten an a ll en ausseren Haarzellen in alle $n$ Windungen angetroffen habe. Was die Befestigung der Membran am Limbus spiralis anlangt, so scheint sie an den Köpfen der hier versenkten Epithelzellen ausserordentlich fest $\mathrm{zu}$ haften.

Irgendwelche Strukturen aber in diesen Epithelien, welche die Ansicht stützen würden, dass sie gerade die Bildner der Fasern der Membrana tectoria seien, war nicht aufzufinden. Die Kittleisten der Köpfe dieser Epithelzellen liegen der Membrana tectoria dicht an.

Wenn ich hier ausdrücklich von versenkten Epithelzellen spreche, so betone ich dies deshalb, weil es mir in Übereinstimmung mit Hensen (21) nicht gelungen ist, einen besonderen Hachen, epithelialen Überzug auf dem Limbus spiralis nachzuweisen, 
wie z. B. Law d owsky (33) einen solchen annahm. Die Zeichnung eines durch Kittleisten begrenzten, flachen Epithels an diesem Orte kommt dadurch zustande, dass die zwischen eigenartig umgewandeltem Bindegewebe versenkten Zellkörper der Epithelien ihren Kopf wie einen Nagel, der im Holze steckt, an der Oberfläche breit hervorschauen lassen, und diese Köpfe sich gegenseitig wie ein flaches Epithel berühren, welches aber nur selten Kerne zeigt (Fig. 49). Die Silbermethoden der Autoren, die ein flaches Epithel hier fanden, stellen Kerne nur unvollständig dar. Dort aber, wo sich solche finden, liegen sie im oberen Teil der versenkten Zelle, sonst aber im flaschenförmig gestalteten Zelleib, weit unter der Oberfläche; manchmal zeigen diese Zellen auch zwei Kerne, deren einer dann ganz oberflächlich gelegen ist. In Fällen, wo das Haften der Membrana tectoria durch ihre fädchenartigen Verbindungen mit den Haarzellen besonders fest. erscheint, zeigt zugleich das ganze $\mathrm{Cortische}$ Organ eine Verziehung im Sinne eines durch Schrumpfung bewirkten Zuges der Membrana tectoria. Diese selbst erscheint weiter aussen am Limbus angeheftet und ist offenbar auf diesem etwas verschieblich wie durch einen zähen Schleim befestigt.

Wi ederkăuer.

Zur Untersuchung gelangten die Gehörorgane von Kälbern und Ziegen. Es wurden entweder die Gehörorgane nach dem Schlachten und der Spaltung des Schädels herausgenommen und direkt fixiert oder am narkotisierten Tier die Fixation durch Injektion in der in der Einleitung geschilderten Weise vorgenommen. Die Maße des Gehörorgans vom Rinde gibt Denker (12). Danach misst die Schnecke $8 \mathrm{~mm}$ im Durchmesser, $6 \mathrm{~mm}$ in der Höhe. Die Weite des Schneckenkanals beträgt basal 2,5 mm. Es sind etwas mehr als drei Windungen vorhanden. Der Ductus cochlearis des Kalbes entspricht im wesentlichen der Schilderung, die von demselben beim Schweine gegeben wurde. Die Dicke der Membrana basilaris ist etwas grösser als beim Schwein; sie betrăgt an der dünnsten Stelle zirka $4 \mu$. Die Zunahme ihrer Breite in den verschiedenen Windungen betrăgt ungefăhr das Doppelte; es ergaben sich ohne Berücksichtigung der untersten und obersten Anteile durch Messung an Radiärschnitten für die basale Windung $200 \mu$, für die zweite Windung $280 \mu$, für die 
dritte Windung $400 \mu$. Das in der tympanalen Belegschicht gelegene Vas spirale ist meist verdoppelt.

Was das Cortische Organ (Fig. 6) betrifft, so ist es auf dem Querschnitt etwas höher als beim Schwein, und zwar beträgt die Höhe des Wulstes (der höchste Punkt liegt in der Gegend der innersten Hensenschen Zellen) in der Basalwindung $84 \mu$, in der zweiten Windung $90 \mu$, in der dritten $105 \mu$.

Für die Ziege beträgt die Breite der Basilarmembran 124, $384,432, u$ in der ersten, zweiten und dritten Windung.

Die Pfeilerzellen sind speziell im Bereich der Basalwindung kurz und gedrungen, ihre Länge nimmt in den oberen Windungen stark zu, eine geringe Krümmung dürfte vielleicht schon im Leben vorhanden sein. Kopfeinschlüsse fehlen. Die Struktur einer durchbrochenen Platte, die die Oberfläche des Aussenpfeilerkopfes zeigt, ist weniger deutlich als beim Schwein. Im Fussteil färbt sich der kegelförmige Fusseinschluss bei Doppelfärbung häufig rot, während die Fibrillen blau sich färben.

Bei der Ziege ist die Stellung der Pfeiler eine besonders auffallende; sie sind nicht durch regelmässige Zwischenräume voneinander getrennt, sondern es sind immer Gruppen von zwei bis drei Pfeilern zu finden, die ganz dicht aneinandergeschmiegt erscheinen, während zwischen den Gruppen grössere Zwischenrăume frei bleiben. Am Kopf und Fuss ist dann das Protoplasma der benachbarten Zellen vielfach eng verwachsen.

Die Deitersschen Zellen zeigen beim Wiederkäuer in der Basalwindung stark entwickelte Stützkelche, in der zweiten Windung sind wirkliche Kelche nicht mehr darzustellen, der „untere Kopf" der Zelle bildet vielmehr nur eine Art Stützpolster für die Haarzelle, in den ein Fortsatz der Stützfaser löffelartig hineinragt. In der obersten Windung ist auch diese Struktur kaum mehr angedeutet. Dagegen treten Typen auf, wie sie Held (20) beim Meerschwein speziell beschrieben, indem in den Stützzellen die kräftigen Fasern stark auseinander weichen. Sehr häufig finden sich Einschlüsse von derberen Brocken mit der Stützsubstanz zusammenhängender und mit ihr sich gleichfärbender Materie (Fig. 27). Der Tragbogen der aussersten Deitersschen Stützzellen ist in den oberen Windungen typisch ausgebildet (Fig. 7). Nicht selten stehen zwei Stützzellenphalangen nebeneinander. Die Innenphalange entspricht ganz der Schilderung, 
die beim Schwein davon gegeben worden ist. Ganz abweichend verhält sich dagegen die Region der Grenzzelle; hier finden wir bei den Wiederkäuern nicht ein ziemlich schmales Element, sondern eine ganze Anzahl, in zwei bis drei Reihen angeordnet, offenbar stiftförmiger, ausserst schmaler Zellen, wie man es besondẹrs in der Ansicht von oben erkennt, wo die kräftigen Kittleisten, die die Köpfe dieser Zellen verbinden, sehr deutlich hervortreten (Fig. 28). Bei schlechter Fixation sieht man von diesen Zellen kaum eine Andentung.

Die Haarzellen sind etwas gedrungener als beim Schwein. Ihre Lange nimmt gegen die oberen Windungen zu. Dies gilt. aber nur für die åusseren Haarzellen, die in der Basalwindung $20 \mu$, in der zweiten $34 \mu$, in der dritten 46 und $50 \mu$ maßen. Die inneren Haarzellen zeigten aber in demselben Falle in allen Windungen eine Länge von zirka $32 \mu$. Dabei beträgt die Länge der Haare bei den äusseren Haarzellen in der basalen Windung ca. $3 \mu$, für die inneren $5 \mu$, in der zweiten Windung 6 resp. $7 \mu$, in der dritten Windung 9 resp. $10 \mu$. Die Länge der Hörhaare nimmt also auch hier an allen Haarzellen zu.

Das Protoplasma der Haarzellen ist beim Wiederkäuer ganz besonders labil und sehr schwer zu konservieren. Kleine Körnchen im Protoplasma finden sich hăufig.

Die Hensenschen Zellen sind sehr lang und schmal, stark nach innen konkav gekrümmt; sie überdecken sich zwiebelschalenartig (Fig. 6). Zuweilen zeigen die innersten zarte Stützfaserbildungen.

Was die anderen Teile des Canalis cochlearis betrifft, so ist bei den Wiederkäuern die reichliche Capillarisierung der Reisnerschen Membran hervorzuheben, die auch elastische Fasern in reichlicher Zahl enthält.

In den höheren Windungen fällt die Höhe der Köpfe der auf dem Limbus spiralis versenkten Epithelzellen auf.

Die Membrana tectoria scheint meist näher dem Rande des Limbus zu inserieren als beim Schwein und den Carnivoren. Die dicken, stark färbbaren Fasern, die in ihren oberflächlichen Grenzschichten vorhanden sind, zeigen eine auffallend starke Ausbildung auch oberhalb des angehefteten Teils. Ganz besonders aber treten sie am freien Rande der Membran hervor. Hier finden sich ganz dicke, verzweigte Wülste einer nicht strukturierten, stark ge- 
färbten Masse der Oberflächenschicht der Membr. tectoria aufgelagert (Fig. 46).

Die Nervenendstellen der Maculae und Cristae bieten bei den Wiederkảuern wenig Spezifisches. Ihr Verhalten entspricht durchaus den beim Schwein dargestellten Einzelheiten. Die Otolithen sind recht klein.

Crista ampullaris.

$$
\text { Pferd. }
$$

Das Epithel der Cristae des Pferdes zeigt im allgemeinen einen typischen Bau, auch verhalten sich alle Teile der Cristae ungefăhr gleichmåssig. Die Zahl der Stützzellen übertrifft die der Haarzellen.

Die Haarzellen sind langgestreckt flaschenförmig, etwa $20 \mu$ lang, an der dicksten Stelle $5 \mu$, an der schmalsten $2 \mu$ breit; am unteren Pol besitzen sie eine glatte, runde Kontur. Sie erreichen die Basis des Epithels niemals. Die Membran der Zelle ist zart. Am Koptteil ist sie durch eine Platte abgeschlossen, die etwa $4 \mu \mathrm{im}$ Durchmesser misst. Der Kern ist oval, 3-4 4 lang und wenig strukturiert. Die am Kopfe der Zelle inserierenden Hörhaare sind meist dicht verklebt, nur selten bringt sie die Fixierung unverklebt zur Ansicht; sie sind kaum messbar fein, sieben oder mehr an der Zahl; die mehr zentral gelegenen scheinen länger zu sein als die weiter aussen stehenden. Das ganze Bündel der Hörhaare ist gegen die Schneide der Cristae hin im Winkel abgebogen (Fig. 29).

Die zwischen den Sinneszellen gelegenen Stützzellen, die mit ersteren durch starke Kittleisten verbunden sind, erscheinen als längliche, basal und kopfwărts verbreiterte Elemente; sie setzen sich im Gegensatz zu den Haarzellen mit ihrer Basis direkt an die Limitans an. Ihre grösste Breite beträgt am Kopfe $8 \mu$, ihre Länge ca. $25 \mu$.

Ihr Protoplasma enthălt feinste Körnchen von braunschwarzem Pigment; letzteres feult den Haarzellen vollständig.

Die Zellen neben dem eigentlichen Sinnesepithel, welche den Übergang zu dem indifferenten Epithel bilden, das den Bogengang auskleidet, sind zylindrisch, 8-9 $\mu$ lang, ca. $4 \mu$ breit; ihre freie Oberfläche erscheint halbkugelig gewölbt, die 3 " langen, ovalen Kerne enthalten spärliche Chromatinkörnchen. Die Zellen enthalten reichlich Pigment, aber in feineren Körnchen als die 
Stützzellen im Bereich des Sinnenepithels. In diesen Zellen und in denen des Übergangsepithels findet man in einer Ecke des unregelmässigen Polygons, das an der freien Oberflăche von Kittleisten eingerahmt wird, das kleine Diplosom. Im Epithel und im darunter gelegenen Bindegewebe fand ich beim Pferd in Übereinstimmung mit Alexanders (1) 'Befund reichlich Pigment, im Bindegewebe auch eigentliche Pigmentzellen.

Die Cupula erscheint als eine zarte Gallerte von feinkörniger Struktur; es erstrecken sich hellere, parallele, dicht gedrängte Streifen von etwa $1 \mu$ Breite bis an ihr oberes Ende. Die Nerven, welche zum Epithel der Cristae ziehen, sind beim Pferd auffallend dick, und zwar ist sowohl der Achsenzylinder als auch die Markscheide der prae- und postganglionaren Fasern um vieles dicker als die Fasern in der Cochlea (Fig. 30). Die Markscheide erreicht eine Dicke von $8 \mu$ und mehr.

Das Epithel der Maculae Sacculi und Utriculi ăhnelt im wesentlichen dem Epithel der Cristae. Die Haarzellen sind etwas länger, $25 \mu$, die Stützzellen entsprechend $34 \mu$ lang. Pigment fehlt an diesen Örtlichkeiten fast vollstăndig.

Was die Schnecke betrifft, so bietet ihre Untersuchung beim Pferd die schwierigste Aufgabe von allen untersuchten Tieren. Die Härte des Knochens, welcher die Schnecke einschliesst, ist eine ungewöhnliche, und seine ganz besondere Sprödigkeit erschwert alle Manipulationen sehr, die man anstellt, um der Fixierungsflüssigkeit einen Zuzug zur Schnecke zu verschaffen.

Die Schnecke des Pferdes zeigt eineetwas geringere Entwicklung als diejenige der Wiederkăuer. Denker gibt für sie an der Basis eine Breite von $7,5 \mathrm{~mm}$ an bei einer Höhe von $2,9 \mathrm{~mm}$. Sie besitzt $21 / 6$ Windungen.

Die oben erwähnten Schwierigkeiten bei der Herstellung der Präparate werden noch erhöht durch das häufige Vorkommen pathologischer Gehörorgane, die man überraschender Weise bei sonst normalen Pferden findet. Mehr als die Hăfte der. von mir sofort nach dem Schlachten konservierten Schnecken, welche durchwegs von nicht besonders alten Tieren stammteu, zeigten Abnormitäten, und zwar ganz in der Weise, wie sie Alexander (2) von albinotischen Carnivoren beschrieben hat und wie sie sich auch beim Menschen finden. Indem nämlich ganze Partien des Cortischen Organs unentwickelt oder atrophiert und durch ein 
flaches Epithel ersetzt erscheinen. Zugleich zeigen die entsprechenden Teile des Ganglion spirale hochgradige Atrophie, so dass man aut Radiarschnitten nur einzelne wenige schmale Nervenfasern und ganz vereinzelte Ganglienzellen sieht. Es ist bemerkenswert, dass in den Abschnitten, in welchen diese hochgradigen Defekte vorkommen, die Membrana tectoria ganz normal ausgebildet erscheint, ein Umstand, auf den schon Hinweise sich in Rickenbachers (42) Arbeit finden. Die Tiere, die diese Abnormität zeigten, waren nicht albinotisch, der Defekt fand sich an beiden Gehörorganen.

Die Elemente des Cortischen Organs erscheinen besonders gross und krăftig, insbesondere zeigen die Stützelemente eine derbe Ausbildung.

Die Pfeiler, deren Köpfe weder Einschlusskörper, noch besondere Oberflăchenbildung zeigen, besitzen sehr derbe Stützfasern, der Phalangenfortsatz der ausseren Haarzelle ist sehr breit und enthält eine grosse Anzahl von Stützfasern, die viel grösser ist als bei den anderen untersuchten Tieren.

Die Deitersschen Zellen zeigen einen sehr kräftigen Phalangenfortsatz. Ihre Stützfasern sind zart und die Stützkelchbildung in den höheren Anteilen des Cortischen Organs schwach entwickelt.

Die Haarzellen sind verhältnismăssig kurz. Sie zeigen deutlich eine dunkle, färbbare Protoplasmapartie in ihrem unteren Abschnitt, dem Retzi usschen Körper entsprechend.

Grenzzellen scheinen als lange, stiftförmige Zellen in zwei Reihen entwickelt $z \mathbf{u}$ sein, in ähnlicher Weise wie bei den Wiederkăuern.

Die Beziehungen des Acusticus zu den Gebilden des Labyrinths sind seit langem Gegenstand regen Interesses gewesen. Je nach dem Stande der Technik hat man bald diese, bald jene Zellelemente der Endorgane im Vorhofsgebiet und in der Schnecke mit den Nerven in Zusammenhang gebracht und für die eigentlichen Sinneselemente gehalten. Was speziell die Beziehungen des Nervus vestibularis zu dem Sinnesepithel betrifft, so hat erst kürzlich Gustav Retzius (41, XII), der Klassiker des Gehörorgans, der Geschichte der Entwicklung dieser wichtigen anatomischen Spezialfrage, an der er selbst lebhaften Anteil genommen 
hat, eine eigene Studie gewidmet. War Max Schultze (43) der erste, welcher die marklos gewordenen Achsenzylinder in das Epithel eindringen sah, so konnte Retzius schon 1871 sagen: „Es gelang 'mir sowohl beim Menschen als beim Hund, beim Kaninchen und bei Fischen, die Nervenfaserenden in unzweideutiger Verbindung mit den Hörzellen zu sehen." 1881 schrieb derselbe Verfasser gelegentlich der Schilderung von Isolationspräparaten der Sinneszellen vom Alligator, wie folgt:,$\ldots$ wie geschieht nun die eigentliche Vereinigung der Nervenfasern mit der Haarzelle? Die Haarzellen sitzen in der Regel mit breiter Basis auf der Nervenfaser, und die auseinander getretenen Primitivfibrillen der letzteren umfassen das untere Ende jeder Haarzelle von allen Seiten her, um schon am unteren Ende der Zelle, unter dem Kerne, zu endigen. Man kann die Nervenfaserchen nicht - wie $\mathrm{P}$. Meyer und $\mathrm{Cis} \mathrm{ow}$ angenommen - höher oben bis zum oberen Ende der Zelle (zum „Cuticularsaum") verfolgen. Die Verbindung mit den Zellen ist übrigens keine lose; ich konnte die Lage der in solcher Verbindung isolierten Zellen in der verschiedensten Weise durch abwechselnden Druck auf das Deckglas veråndern, bald sah ich sie von der einen, bald von der andern Seite, bald von oben an und sie lösten sich von ihrer betreffenden Nervenfaser erst durch verhalltnismässig gewaltsames Eingreifen. Ich konnte mich deswegen durch mannigfache Manipulationen von der Art ihres Zusammenhanges überzeugen. Es kann hiermit nicht von einem Anlegen der Primitivfibrillen an die Zelle, noch weniger von einem Ankleben die Rede sein, sondern meiner Ansicht nach sind die Zellen organisch mit den Nervenfasern vereinigt, indem die Fibrillen in der Substanz der Zelle endigen." (S. 23.) Weiter unten sagt derselbe Autor: „Die Haarzellen sind also nach meiner Ansicht als die einzigen Endorgane des Gehörnerven anzusehen." Nach der damals üblichen Methode war es nicht schwer, in den Maculae und Cristae des Labyrinths die Nerven bis zu den Sinneszellen zu verfolgen. Auf Schnitten und Isolationspräparaten, unter Anwendung von Chromsalzen und Osmiumsäure, wurde damals von den meisten Forschern die Ansicht von Retzius ungefähr bestätigt, nämlich, dass die Fasern des Vestibularis mit den Sinneszellen in letzter Linie in Zusammenhang stünden. Aber diese Fasern verloren ihre Markscheide vorher, und die histologische Technik der damaligen Zeit verfügte über 
kein Hilfsmittel, um den marklosen Anteil der Nerven in genügend klarer Weise zur Darstellung zu bringen. Der Versuch, auf Grund von Osmium- und Goldchloridpräparaten diese Frage zu entscheiden, führte von Ebner (15) zu der Annahme, dass die Sinneszellen in einer durch Goldchlorid färbbaren, krümeligen Substanz eingebettet lägen, die aus dem Plexus und den interepithelialen Nervenenden zusammengesetzt seien.

Die Einführung der Chromsilbermethode dureh Golgi brachte eine Nenerung.

Unter Anwendung dieser Methode gelang es Retzius, Lenhossek (34) und van Gehuchten, die Fasern bis zu den Zellen und zwischen die Zellen zu verfolgen. Gleichzeitig wurde auf Grund der Bilder, welche die Chromsilbermethodik lieferte, das Gebăude der Neuronenlehre aufgeführt, jene Lehre, die bis in die jüngste Zeit heiss umstritten wird, und die im Nervensystem ein Mosaik von durch Berührung miteinander in Verbindung stehenden Zellindividuen sieht. Für die Anhänger dieser Lehre ist die Ganglienzelle des Vestibularis bezw. Cochlearis mit ihrem Auslăufer gegen die Sinneszelle hin und ihrem Fortsatz ins Zentrum hinein ein in sich abgeschlossenes Zellindividuum, ein Neuron, die Sinneszelle eine zweite, in sich abgeschlossene Zellindividualität, wenn sie auch nicht so ganz allgemein als Neuron bezeichnet wird. Beide Zellen sollen ausschliesslich nur durch Kontakt in Verbindung stehen und ihr funktioneller $\mathrm{Zu}$ sammenhang dadurch zustande kommen, dass, da beide sich aus getrennten, embryonalen Zellanlagen entwickeln, der Fortsatz der Ganglienzelle gegen die Basis der Sinneszelle hinwächst und sich an diese innig anlegt. 1892 sagt Retzius bei Besprechung von Präparaten neugeborener Mäuse nach Golgis Methode: „... die Haarzellen sind deshalb keine Nervenzellen. Alle Nervenfasem des Gehörnerven scheinen peripher verlaufende Fortsătze der bipolaren Ganglienzellen zu sein, und alle Haarzellen sind als sekundäre Sinneszellen aufzufassen." In ähnlicher Weise sprach sich auch van Gehuchten in den Verhandlungen der anatomischen Gesellschaft zu Wien, 1892, aus. Aber nicht alle Forscher gelangten auch mit der Chromsilbermethode zu den gleichen, übereinstimmenden Resultaten. So sprach sich Ayers (3) auf Grund von Golgi praparaten von Embryonen und von erwachsenen Tieren und auch Menschen dafür aus, dass eine Konti- 
nuităt zwischen den Nerven und den Sinneszellen bestünde. Dieser Befund wurde fast allgemein mit Kopfschütteln abgetan, und da A y ers die Fasern aus der Sinneszelle entspringen liess, wăhrend verschiedene andere Autoren mit grosser Bestimmtheit behaupteten, dass die Fasern aus den Embryonalzellen der Acusticusganglien gegen die Epithelien hineinwüchsen, wurke den Ausführungen Ayers wenig Beachtung geschenkt. Zwar hat auch Retzius Zellen im Zusammenhang mit Fasern nach der Chromsilbermethode gefurbt gesehen, wie er es selbst abbildet. (Biologische Untersuchungen VIII, 7.) Er hielt aber diese Bilder für eine zufällige Imprägnation. Später, als durch $\mathrm{Ehrlich}$ die vitale Methylenblaufärbung entdeckt worden war, haben verschiedene Forscher versucht, mit Hilfe dieser Methodik über die Lageverhaltnisse der Acusticusfasern zum Sinnesepithel sich Klarheit zu verschaffen. Dies geschah bei niedern Wirbeltieren und auch bei Săugern durch $\mathrm{Ni}$ em a ck, Kaiser und Ret $\mathrm{zi}$ is. Niemack schilderte auf Grund der Methylenblaupräparate die Verhältnisse wie folgt: „Aus dem Plexus steigen Füserchen von zweierlei Art auf. Die einen endigen frei, die anderen treten $z \mathbf{u}$ ein oder mehreren an die untere Gegend der Haarzellen, wo sie bald aufhören. Zwischen Nerv und Zelle scheint eine Art Zwischensubstanz die Kommunikation zu vermitteln, so dass wir weder eine Kontinuitat noch eine direkte Kontiguität haben. In ahnlichem Sinne hat sich später auch $\mathrm{Krause}$ ausgesprochen.

Nachdem schon in den achtziger Jahren Retzius auf Grund seiner Osmiumisolationspräparate neben scheinbar frei endigenden Fäserchen kelch- und schalenartige Bildungen beschrieben hatte, fanden auch Niemack, Geberg und Krause mit der vitalen Methylenblaumethode diffus blau gefarbte Kelche, welche bald nur den unteren Teil, bald fast die ganze Haarzelle umgeben sollten. Dagegen meinte Lenhossek 1893, dies bestreiten zu müssen; er glaubte nur, dass Varikositäten der Nerven die Spur des Kontaktes tragen: „Eine kelchartige Ausbreitung des ungeteilten Achsenzylinders um die Haarzellen herum muss ich nach meinen Präparaten durchaus in Abrede stellen." $-\mathrm{R}$. Krause sagt bei Besprechung der Verhăltnisse bei Säugern: „Die Faser verdickt sich an ihrem peripheren Ende allmahlich und geht ohne irgendwie deutliche Grenze in den Körper der Haarzelle über." ${ }_{n}$ Auch ich konnte, wie Niemack, bemerken, dass sich die peri- 
phere Zone des Zellprotoplasmas beträchtlich intensiver färbt als das Zellinnere." - Retzius bemerkt hierzu, dass dies keine spezifische Eigenschaft der Haarzellen, sondern der verschiedensten Zellen bei Methylenblaufärbung sei.

Es bestanden also bis in die letzten Jahre drei verschiedene Auffassungen über die Endigungsweise der Fasern des Hörnerven an den Sinneszellen.

Erstens: die Fasern enden zwischen den Epithelzellen und an ihnen und stehen mit ihnen in innigem Kontakt.

Zweitens: die Fasern endigen in der Substanz der Haarzellen oder entspringen aus ihnen.

Drittens: die Fasern verbreitern sich kelchartig und umfassen innig das untere Ende der Haarzelle.

Wie wir in Folgendem sehen werden, enthielten alle diese Lehren einen Teil der Wahrheit, ohne aber die vorhandenen Tatsachen $z \mathbf{u}$ erschöpfen.

Im Jahre 1903 hat Ramon y Cajal (8) eine neue Methodik für die Darstellung der nervösen Elemente angegeben, die Methode des "reduzierten Silbers". Diese erlaubt, in viel feinerer Weise die Nervenenden darzustellen, als es bisher möglich war. Schon in einer seiner ersten Arbeiten auf Grund dieser Methode berücksichtigt $\mathrm{Cajal}$ auch das Labyrinth, das er an Hühnerembryonen beschreibt. Dabei betont er die fundamentale Tatsache, dass wenigstens im Gebiete des Vestibularis und zuweilen in den Cristae sich zweierlei Nervenfasern finden: zarte, die zwischen den Epithelien mit Knöpfchen endigen, und sehr dicke, die kelchartig eine oder aber gewöhnlich mehrere Zellen umfassen. Er bestatigte somit die Darstellung, die Retzius in den achtziger Jahren gegeben hatte.

Als ich mit dieser Methodik Versuche anstellte, ergab sich aus den Bildern der Eindruck, dass Cajal diese Frage nicht bis ans Ende verfolgt hatte und das Wichtigste in der Darstellung des Verhaltens der Nerven noch übrig gelassen habe. Ich hatte zufällig ein besonders günstiges Objekt, das Labyrinth des Frosches, zur Untersuchung gewăhlt. Hier fanden sich neben interepithelialen überall in den Sinneszellen intraepitheliale Fibrillengeflechte. Dieser Befund liess sich bei Vögeln (Gans, Taube) mit derselben Klarheit, schwer bei Selachiern und Knochenfischen, besonders. leicht bei Nagern (Kaninchen, Maus) erheben. Im Anatomischen 
Anzeiger sind die betreffenden Befunde vorläufig dargestellt. Seither konnte ich dasselbe wenigstens für den Vestibularapparat des Labyrinths auch bei den grossen Säugern (Schwein, Pferd) feststellen. Besonders schöne Bilder lieferten mir Gans, Katze und insbesondere Mensch. Letztere Präparate konnte ich der Naturforscherversammlung in Meran 1905 und der Morphologischen Gesellschaft in Wien vorlegen. Diese meine Befunde wurden nun auch bei der weissen Maus von London (35) und neuerdings von London und Pesker (36) bestätigt.

In neuester Zeit hat auch Rudolf $\mathrm{Krause}(30)$ in einer sehr eingehenden nnd detaillierten Arbeit sich mit der Innervation der Sinneszellen im Labyrinth befasst, und zwar beim Flussneunauge. Es ist leider der Arbeit nicht zu entnehmen, ob die Untersuchung durchwegs an geschlechtsreifen Petromyzonten oder an dem häufiger zugänglichen Material der Ammocoeten vorgenommen wurde. Ich besitze über die Anwendbarkeit der Silbermethoden nur bei letzteren einige Erfahrung, sie erwiesen sich, wie übrigens die meisten Fische, für die Darstellung der Fibrillen in peripheren Organen als ein höchst ungünstiges Objekt, was vielleicht in spezifisch physikalisch-chemischen Eigentümlichkeiten des Fischprotoplasmas seinen Grund haben dürfte. Deshalb erscheint es mir ganz begreiflich, dass es Krause nicht gelang, die Fibrillen im Zellkörper darzustellen.

Dabei möchte ich betonen, dass Untersucher dieser Frage sich nicht abschrecken lassen mögen, wenn sie einige Zeit lang keine interzellularen Fibrillen in den Sinneszellen and deren Zusammenhang mit denen des Nerven zu Gesichte bekommen. Die Launenhaftigkeit der Methodik, die nur gerade bei gewissen Tieren, wie schon $\mathrm{Cajal}$ hervorhob, besonders gut gelingt, bringt es mit sich, dass man manche Serie durchstudieren muss, bis eine vollständige Darstellung der Fibrillen die wirklichen Verhăltnisse erkennen lässt, wăhrend unvollkommene Färbungen das Bestehen von Verhältnissen, wie sie $\mathrm{Krause}$ in Übereinstimmung mit Retzi us beschreibt, zu bestatigen scheinen.

Das Verhalten der Fasern des Vestibularis ist in kurzem folgendes: Die markhaltigen Fasern ziehen von den Ganglien in ziemlich direkter Richtung gegen das Epithel der Cristae und Maculae; sowohl die Markscheide als der Achsenzylinder sind verhältnismässig dick, bei allen Tieren deutlich dicker als die 
Fasern der Cochlearis. Zwischen den dicken Fasern finden sich auch einige zartere. Beim Eintritt ins Epithel verlieren die Fasern die Markscheide und zwar entweder indem sich diese zu einem immer zarter werdenden Konus verdünnt, so dass mar. ihre eigentliche Grenze kaum wahrnehmen kann, oder indem siehalbkugelig sich absetzt und plötzlich aufhört, sowie etwa an einer R a nvi e rschen Einschnürung. Die Markscheide zeigt sich bei Osmiumfärbung homogen; bei Silberfixierung entspricht ihr ein mit zarten, geschrumpften Massen erfüllter Spaltraum in jenen Fällen, wo der Achsenzylinder distinkt gefürbt ist; wo dieser blass erscheint, ist die Markscheide kaum zu sehen. In einzelnen seltenen Fallen erzeugt das Silber das Bild eines ausserordentlich groben "Neurokeratinnetzes". Bei Fixierung mit Kali-BichromatFormalin-Eisessig oder Peren $n y$ is Lösung und nachfolgender Eisenhămatoxylinfärbung erscheint dagegen ein sehr engmaschiges, dichtes, aus feinsten Faden bestehendes Neurokeratinnetz. Nach Verlust der Markscheide zieht der Achsenzylinder entweder gerade auf die Sinneszelle zu oder, im Winkel umbiegend, zu einer entfernteren Zelle. Sehr haufig sieht man den Achsenzylinder sich teilen und gleichzeitig an mehrere Zellen herantreten. Im Bilde guter Osmiumfixierung und Fuchsinfärbung sowohl als auch im Cajalschen Silberbild sowie bei der Anwendung der Bielschowskischen Methode sieht man, dass ein eigentlich echter Plexus, wie ihn verschiedene frühere Darstellungen zeigen, nicht vorhanden ist. Das Bild eines solchen kann zustande kommen, wenn die eben besprochenen Fasern mit den noch zu erwähnenden interepithelial endenden Fasern zugleich partiell gefärbt. erscheinen. - Unterhalb der Zelle weichen die früher eng aneinander gedrängten und parallel verlaufenden Neurofibrillen des. Achsenzylinders auseinander. Man kann dies besonders deutlich im Fibrillenbild der beiden Modifikationen der Cajalschen Methode sehen, aber auch an Osmiumfuchsinpräparaten und bei der Kalibichromat-Formol-Eisessig-Fixierung und Alsolhämatoxylinfärbung, die Held empfohlen hat, hinlänglich unterscheiden. Das Bild entspricht vollkommen demjenigen, das $\mathrm{Ret} z \mathrm{i}$ us vom Alligator gegeben hat (Fig. 29). Am unteren Pol der Zelle angelangt, treten die Fibrillen direkt in das Protoplasma der Sinneszelle ein und bilden etwa ein halbes Mikron unter der Oberflache des Zellkörpers unter fortwährenden Anastomosen und Verzweigungen 
einen basalen Gitterkelch. Von diesem Kelch aus erstrecken sich dann Gittermaschen in den verschiedensten Formen neben dem Kern hinauf bis gegen die Oberfläche der Zelle hin. In den sehr seltenen Fallen, in denen sowohl die Fixierung als die Färbung des peripheren Teils der Sinneszelle besonders gelungen ist, sieht man auch unter der Deckplatte der Zelle geschlossene Gittermaschen (Fig. 32). Meistens aber lăsst die Darstellung dieser letzteren Maschen zu wünschen übrig, da das Protoplasma hier meist starke Zerfallserscheinungen zeigt.

Dass es sich bei den durch die Silberfärbung hier dargestellten Strukturen wirklich um die Fărbung von den Neurofibrillen des Achsenzylinders entsprechenden Fibrillen im Protoplasma der Zelle handelt und nicht um die Färbung anderer, intracellulărer Fåden, Trophospongien, Wabenwände und dergleichen, geht daraus hervor, dass erstens bei gut gelungener Fărbung die Form und Anordnung der Maschen stets eine gleichartige ist, dass zweitens die Gittermaschen sich durch eine typische Form schmaler, langer Spitzbogen von imprägnierten Protoplasmawaben deutlich unterscheiden, drittens, dass die Fibrillen in genau gleichem Farbenton mit denen des Achsenzylinders gefärbt erscheinen, während in allen andern Gewebselementen des Präparats, abgesehen von Ganglienzellen, nichts ähnliches zu finden ist, und daneben häufig in der gleichen Zelle in einer ganz anderen Farbennüance Trophospongien dargestellt erscheinen. Wie gesagt, lässt die Fürbung und Fixierung des oberen Zellendes meist $\mathrm{zu}$ wünschen übrig, immerhin scheint, soweit die fărberische Differenzierung und die optische Auflösbarkeit der Gebilde derzeit erkennen lässt, ein Zusammenhang mit dem kleinen Einschlusskörper und den Sinneshaaren, die auf ihm wurzeln, mit dem Fibrillengitterwerk in der Zelle nicht zu bestehen.

Ausser den Nervenfasern, die sich in der eben geschilderten Weise verhalten, findet sich noch eine zweite Gattung von Fasern vor, welche - wie es Cajal bereits beim Hühnerembryo beschrieb - nach mebrfachen Verzweigungen mit Endknöpfchen zwischen den Epithelien endigen. Diese Endknöpfchen enthalten neben der perifibrillären Substanz eine Endschlinge, die sich aber nur höchst selten darstellen lässt. Am leichtesten sieht man diese zweite Art der Nerven bei den Vögeln (Gans, Taube). Hier erscheint vorzugsweise der abfallende seitliche Teil der 
Cristae von ihnen innerviert, während diese Endigungen neben den anderen Fasern, deren Fibrillen mit denen der Zellen zusammenhängen, in der Mitte des Sinnesepithels fast ganz zurücktreten. Die interepithelial endigenden Fasern scheinen bei der Silberfärbung um vieles dünner zu sein als die anderen. Cajal (7) und Retzius (41, XII) nehmen an, dass das geschilderte Verhalten speziell für die Cristae charakteristisch sei, ich habe aber bei Vögeln beide Arten der Innervation, auch in der Macula utriculi und Macula sacculi, gefunden. Bei den Săugern habe ich mir viele Mühe gegeben, um über diese Verhaltnisse ins klare zu kommen. Es gelang mir, in der Maculae und Cristae der Katze einige wenige Nervenfasern des zweiten Typus (zarte Fasern mit freier Endigung) zwischen den vielen mit dem intracellulären Fibrillengitter in Verbindung stehenden dicken Fasern zu finden (Fig. 31). Die Endigungen selbst sind selten und schwierig zu sehen. Bei der Maus konnte ich trotz Durchmusterung einer grossen Zahl von Schnittserien durch das Labyrinth verschieden alter Embryonen und erwachsener Tiere derartige Fasern bisher nicht entdecken. (Beim Menschen glaube ich, einige spärliche Andeutungen solcher Fasern in einer Macula gesehen zu haben.) Es scheinen sich eben gerade bei Anwendung der $\mathrm{C}$ ajalschen Methode die Fasern dieses zweiten Typus schwer darstellen zu lassen. Ein Unterschied bezüglich der topographischen Verteilung beider Fasergattungen in bezug auf Zentrum und Peripherie der Sinnestläche, wie er bei Vögeln auffallt, lässt sich beim Såuger nicht konstatieren.

Die hier besprochienen histologischen Verhältnisse im Epithel der Maculae und Cristae liessen sich auch beim Menschen ohne grosse Schwierigkeit darstellen. Sie entsprechen hier durchaus allem, was sich bei kleineren Såugern, z. B. der Katze, findet. Leider konnte ich bisher am menschlichen Naterial die Frage nicht erschöpfend studieren, da mir das nötige, absolut frische Material nicht zur Verfügung stand; auch unter günstigsten Umständen vergehen mehrere Stunden nach dem Tode, bis das herauspräparierte häutige Labyrinth in die Fixierungsflüssigkeit eingelegt werden kann. Infolgedessen sind die Zellen immer schon etwas gequollen und maceriert. Dennoch ist das Gittermaschenwerk, das basal dichter, aber auch im ganzen Zellkörper und oberhalb des Kernes ziemlich enge ist, vorzüglich klar zu 
sehen (Fig. 33), Die Sinnesepithelien des Erwachsenen zeigten ein noch dichteres Gitterwerk als die des Neugeborenen (Fig. 34). Über das Forkommen der Fasern des zweiten Typus möchte ich noch kein Urteil abgeben.

Es mag nach dieser Schilderung der Beziehungen der Nerven und ihrer Endfibrillen merkwürdig erscheinen, dass so viele ausgezeichnete Untersucher zu von der hier geschilderten so gänzlich verschiedenen und einander widersprechenden Auffassungen der Sachlage gekommen sind. Es wird aber demjenigen weniger merkwürdig erscheinen, der sich der Mühe unterzieht, die verschiedensten histologischen Methoden am Labyrinth zu erproben; denn die von den Autoren erhaltenen so ungleichen Bilder, die immer als der Ausdruck der tatsächlichen Verhältnisse aufgefasst wurden, erklären sich leicht aus den Einflüssen der Methodik. Man halte sich vor Augen, dass die Epithelien des Labyrinths zu den labilsten tierischen Zellen gehören. Betrachtet man die Elemente frisch, so ist es kaum möglich, Nerv und Zelle sofort so zu lagern oder zu isolieren, dass man sicher wăre, nicht künstliche Veränderungen herbeigeführt zu haben. Auch wenn es einmal durch Zufall gelingt, frische Objekte so auszubreiten, dass man die unteren Enden der Haarzellen günstig betrachten kann, verändern sich die im Leben bestehenden Verhältnisse durch Quellung und Vakuolisierung auch im indifferentesten Medium sehr bald.

Osmiumsäurebehandlung lässt manchmal viele Details in richtiger Weise erkennen, aber auch durch ihre Anwendung verändern sich manche Lageverhältnisse stark. Wirkt sie zu schwach ein - sie dringt bekanntlich nur sehr schwer durch die Gewebe - so zerfallen einzelne Teile der letzten Nervenstrecke, ehe sie die Basis der Sinneszelle erreichen; wirkt sie zu stark ein, so werden die fixierten Nerven brüchig, und es treten auch an der anfänglich gut fixierten Sinneszelle Schrumpfungen auf. Bei Fixierung mit verschiedenen, osmiumsäurehaltigen Gemischen und anderen Reagentien kommt auch sehr häufig ein Trugbild zustande, indem unter Vakuolisierung der Zelle ein Oberflächenhäutchen und zarte Protoplasmateile sich vom zentralen, kernhaltigen Teil der Zelle ablösen und in Zusammenhang mit den benachbarten Stützelementen und Nerven bleiben, während der zentrale Teil, in der Mitte eines Schrumpfraums zurückgezogen, 
nur durch einzelne feine Fäden geschrumpften Protoplasmas mit. dem åusseren in Verbindung bleibt. Auf diese Weise kommt häufig das Bild von Kelchen und Schalen zustande, aus denen die Zellen (aber eigentlich nur der zentrale, kernhaltige Teil) herausgefallen sind.

An Osmiumisolationspräparaten olne die durch Einwirkung starken Alkohols bedingte Schădigung tritt der besprochene Übelstand seltener auf und so hat auch Retzius mit Hilfe dieser Methode Bilder erhalten, die den Tatsachen am nächsten kommen. Freie Endigungen wurden mit Osmiumsäure nur höchst selten zur Anschauung gebracht. Diese wurden mit Hilfe der Chromsilber- und Goldmethoden gesehen. Die Chromsilbermethode aber, die in unberechenbarer Weise Gebilde verschiedener Art mit einem zarten Niederschlagshăutchen überzieht und Silhouettenbilder liefert, fărbt gewöhnlich nur die freiendigenden Fasern; die Fasern aber, deren Fibrillen basal sich in die der Zelle fortsetzen, nur unvollstăndig. Die vitale Methylenblaumethode, mit der verschiedene Autoren gearbeitet haben, ist vom biologischen Standpunkt aus wohl am einwandfreiesten, aber anch sie krankt heute noch immer an der Verganglichkeit der Bilder im frischen Zustand und ibrer starken Veränderung durch alle bisher zur Fixation vorgeschlagenen Reagentien; bei dieser Methode summieren sich also postmortaler Zerfall und Veränderung durch die Fixierung. Häufig kommen dabei an den Enden der Nerven und in ihrem Verlauf Bilder von Körnchen zustande; ich weiss nicht, ob diese mit den Körnchen, welche nach anderen Behandlungsweisen färberisch sich darstellen lassen und die $\mathrm{Held}$ als Neurosomen bezeichnet, identisch sind. Wenn die Masse der Körnchen zunimmt, wie dies auch bei der Goldbehandlung hăufig auftritt, entsteht das Bild einer körnigen Zwischensubstanz, in der die Zellen stecken. Diese Färbungen sind eigentlich nur eine Darstellung der perifibrillaren Substanz, Gold und Methylenblau tärben die Neurofibrillen nur ausnahmsweise, im Gehörorgan nie. Häufig färbt sich mit Methylenblau intensiv die Oberflächenschicht, die sich - wie eben besprochen - vom zentralen Teil der Zelle bei der Fixierung abhebt und auf diese Weise Kelchbilder liefert.

Schrumpfungserscheinungen können auch das Bild feiner, variköser Fädchen an der dabei meist geschrumpften Oberfläche der Zelle vortăluschen. Bei prall und glatt fixierten Zellen finden sich 
derartige Bilder nicht. Auch die Cajalsche Methode in ihren beiden Modifikationen ist leider, was die Erhaltung der Zellgestalt. betriffit, nicht ganz ideal. Auch geschieht es dabei nicht selten, dass einerseits Fibrillen teilweise ungefärbt bleiben, anderseits Mitfärbung von Protoplasmateilen zustande kommt.

Besonders häufig kommt dies am unteren Pol der Zelle zustande. Es imprăgnieren sich einzelne Maschen samt ihrer Zwischensubstanz mit Silber (Fig. 38), die höher in der Zelle gelegenen Gittermaschen nur unvollständig (Fig. 42), und auch dies kann als Kelch mit aufsteigenden Fäden (Fig. 39) aufgefasst. werden. Erst wer Hunderte von Labyrinthen nach dieser Methode untersucht hat, wird sich über deren Resultate vollkommen klar sein, und es muss davor gewarnt werden, unvollkommene Färbungen als vollkommene anzusehen. Es ist durchaus nötig, bei Entscheidung derartiger Fragen ein grösseres, gleichartiges Material zu verwerten.

Es drängt sich uns natürlich die Frage auf: Wie kommt das Fibrillennetzwerk im Zellkörper zustande und in welcher Weise erfolgt seine Verbindung mit den Neurofibrillen des Achsenzylinders? Vier Möglichkeiten lassen sich für diese Entstehung in Betracht ziehen. Erstens: es können sich die Fibrillen im Protoplasma der Sinneszelle selbständig entwickeln und dann mit. den Fibrillen des Achsenzylinders in Zusammenhang treten resp. wirklich verwachsen. Zweitens: es könnten die Fibrillen, von der Ganglienzelle her, auf dem Wege des Achsenzylinders in die Sinneszelle einwachsen. Drittens: könnten die Achsenzylinder und die Fibrillen mit ihnen aus der Sinneszelle auswachsen, wie Ayers (3) es annehmen wollte. Schliesslich viertens könnte, etwa wie es Hensen sich vorstellte, aus sehr früher embryologischer Zeit ein kontinuierlicher, interzellularbrückenartiger Zusammenhang zwischen Ganglienzellfortsatz und Sinneszelle bestehen und aus diesem sich dann der nervöse Zusammenhang entwickeln. Die letztgenannte Möglichkeit dürfte auf Grund der Tatsachen, die über die Entwicklung des Labyrinthes einerseits, der dazu gehörigen Ganglien anderseits bekannt sind, kaum in Rechnung zu ziehen sein. Welche Aufschlüsse ergeben nun die Bilder, die man mit Hilfe der Cajalschen Methode an embryonalem Material erhalten kann (auch die Bielschowskische Methode gibt hier oft sehr gute Resultate) in bezug auf die drei 
anderen Entwicklungsmöglichkeiten? Ich habe versucht, dieser Frage speziell bei Embryonen der weissen Maus năher zu treten, da dieses Material mir bessere und konstantere Bilder lieferte als das gewöhnlich verwendete von Hühnerembryonen. In frühen Embryonalstadien erhielt ich im Gebiete des Labyrinths keinerlei Fibrillenfärbung. In den Stadien, in welchen die Färbung gelang (Embryonen von $8 \mathrm{~mm}$ Scheitel-Steisslänge), fand sich im Octavus wie in den anderen Gehirnnerven ein starkes Bündel ăusserst klar und distinkt gefärbter, kaum messbar feiner Fäserchen; diese lassen sich unschwer einerseits gegen die Anlage in der Oblongata, anderseits zu den spindelförmigen Ganglienzellen der Acusticusganglienanlage verfolgen, in denen in diesen Stadien nur einzelne wenige Fibrillen, anscheinend durchziehend, gefunden werden. Von den Ganglien peripherwärts lassen sich die Fasern bis in die Epithelanlage des Labyrinths hinein verfolgen, wo die eigentlichen Sinneszellen noch nicht differenziert sind, sondern bloss die Anlage der Sinnesflächen durch die Verdickung des Epithels gekennzeichnet ist. Wie hier die Fåserchen endigen, war nicht $\mathrm{zu}$ ermitteln. Irgendwelche endständige Verdickungen waren niemals zu sehen, eher noch das Auslaufen in eine feine Spitze, an der die Furbung eine Grenze fand, obne dass man den Eindruck gewonnen hatte, dass es eine wirkliche Endigung sei. Hier versagt einfach die Farbung. In diesem Stadium zeigt sich in den Epithelzellen nichts Auffallendes; aber schon in wenig alteren Stadien (Embryonen von 10 und $11 \mathrm{~mm}$ Scheitel-Steisslänge) finden wir im Epithel die Fibrillen im Beginn ihrer Ausbildung; und zwar scheinen sich, soweit ich es bisher beurteilen kann, die ersten Maschen dicht unterhalb des Kernes zu entwickeln, von hier wachsen dann Gittermaschen in den unteren, homogen aussehenden Zellpol hinab, während andere, zu Seiten des Kernes, zur freien Zelloberflache streben (Fig. 36). Bei der weiteren Entwicklung an alteren Embryonen finden wir dann das Gitterwerk dichter, es rückt immer mehr an die Oberfläche der Zelle, bis es ganz dicht unter derselben liegt (Fig. 37). In diesen Stadien finden wir konstant die Fibrillen der Achsenzylinder kontinuierlich in die am unteren Zellpol gelegenen Maschen des Sinneszellengitters eintreten (Fig. 37).

Die hier beschriebenen Entwicklungsvorgänge spielen sich, soweit ich es bis jetzt übersehen kann, an Maculae und Cristae 
gleichzeitig ab. Die nervösen Bahnen im Cortischen Organ, die weiter unten besprochen werden sollen, sind dagegen immer um ein beträchtliches in der Entwicklung zurück, und zwar scheinen anch hier die inneren Haarzellen den ausseren und die erste Reihe der ausseren der zweiten und dritten, was die Ausbildung des Fibrillengitters und das in Zusammenhangtreten mit den Nervenfäserchen betrifft, vorauszueilen, die proximalen Teile der Papilla basilaris den distalen.

Wie schon früher erwăhnt, reichen diese Bilder meines Erachtens doch nicht aus, ein definitives Urteil über die Genese des kontinuierlichen fibrillären Zusammenhanges zwischen der Acusticusganglienzelle und den Sinneszellen zu bilden. London und Pesker (36) nehmen bei Besprechung desselben Vorganges an, dass erst das Hineinwachsen der Nervenfasern ins Epithel gleichsam den Anstoss găbe zur Bildung des Fibrillengitters in den Sinneszellen. Es scheint mir nicht viel damit gewonnen, wenn man den Achsenzylindern diesen nicht näher definierbaren Einfluss zuschreibt, der nur allzusehr an die vielbestrittene Vorstellung von trophischen Nerven erinnert. Das Auswachsen des Achsenzylinders aus der Sinneszelle scheint aber auch nach den Bildern der Cajalschen Methode als ausgeschlossen.

Der ganze Vorgang würde also am meisten dem etwa entsprechen, was Held unter dem Namen "Conkretion" zwischen verschiedenen Nervenzellen versteht. Eine wirkliche Verwachsung, und zwar in der Weise, dass durch Verschmelzung der Fibrillensubstanz eine wirkliche Kontinuität der Fibrillen zustande käme, während die Inter- und Perifibrillarsubstanz des Achsenzylinders mit dem Protoplasma der Sinneszelle in das Verhältnis innigster Berührung trăte.

Zum Schlusse möchte ich noch erwähnen, dass sich die eben besprochenen Verhältnisse auch bei den grossen Săugern, speziell beim Rind, der Ziege, schwerer beim Schwein und beim Pferd darstellen liessen.

Wir stossen da hăufig auf eigenartige Bilder, speziell beim Kalb und der Ziege, indem nicht nur, wie ja bekannt, die Fibrillen eines Achsenzylinders mehrere Zellen versorgen, das heisst, mit ihrem Fibrillengitterwerk in Verbindung stehen, sondern häufig auch eine Zelle mit Fibrillen zweier verschiedener Achsenzylinder in Verbindung steht (Fig. 35). Diese überraschende Kontinuitãt 
zweier Neuronen an der Peripherie lässt sich mit voller Deutlichkeit beobachten. Ob solche Elemente etwa zu einer funktionellen Einheit verbunden sind, muss einstweilen dahingestellt bleiben. Die im vorstehenden geschilderte Entwicklung der Innervation ergibt verschiedene Erklärungsmöglichkeiten für das Zustandekommen solcher merkwürdiger Verbindungen.

\section{Innervation der Schnecke.}

Bietet uns das Studium der Innervation der Maculae und Cristae Schwierigkeiten, so gilt dies noch in viel höherem Maße von der Innervation des Cortischen Organs. Denn wir finden hier marklose Fasern auf eine viel lăngere Strecke hin verlaufend, ja diese ziehen sogar eine Strecke weit frei durch mit Endolymphe erfüllte Răume.

Wenn wir von den älteren Vorstellungen hier absehen, so gehen die herrschenden Anschauungen dahin (Retzius [41], EbnerKölliker [14]), dass die vom Ganglion spirale kommenden Nervenfasern, nachdem sie ihr Mark verloren haben und nachdem sie durch die Habenula perforata durchgetreten sind, zum Teil an die Basis der inneren Haarzellen treten, wăhrend die übrigen, nachdem sie den Tunnelraum durchlaufen, an den äusseren Haarzellen mit kleinen Knöpfchen endigen. Cannie u (6) und Held (20) haben an der Basis der Haarzellen nicht nur einen, sondern mehrere Endknöpfe beschrieben. Dabei betont Held ausdrücklich, dass die Haarzellen nur am unteren Pol mit nervösen Gebilden in Verbindung traten nnd nicht, wie er es von den Sinneszellen der Cristae und Maculae beschreibt, von Neuritenprotoplasma ein erhebliches Stück weit eingehüllt wären. Es haben also die Autoren bisher übereinstimmend nervöse Fäserchen und Knöpfchen im Cortischen Organ ausschliesslich am unteren Pol der Sinneszellen gesehen, aber nichts derartiges im Verlaufe oder langs des Haarzellenkörpers. Es würde also gemåss dieser Anschauung ein in der Sinneszelle auftretender Erregungszustand zuerst durch deren Protoplasma weiter geleitet werden und erst am unteren Pol der Zelle auf die spezifische, leitende Substanz der Nervenfaser übergehen können.

Bei ausgewachsenen Säugern lässt sich mit den jetzt bekannten Methoden bloss folgendes beobachten. 
Die vom Ganglion abgehenden Nervenfasern verlaufen vorwiegend in radiarer Richtung, sie sind aber mit spiral verlaufenden Zügen durchsetzt. Ranviersche Einschnürungen sieht man an ihnen hăufig. An der Habenula perforata angelangt, verlieren sie ihre Markscheide und treten, zu dichten Bündeln zusammengeschlossen, durch die engen Nervenlöcher durch. Von hier $a b$ ist schon ihr weiterer Verlauf schwer zu sehen. In jenem Raum, welcher zwischen Grenzzelle, Innenphalange und innerer Haarzelle gelegen ist, sind die Fasern schwer darzustellen, und die besondere Hinfälligkeit der epithelialen Gebilde bewirkt es, dass deren meist schlecht konservierte Basalteile das Bild dieser Gegend verwirren. Immerhin gelingt es an mit der Biels chowskischen Methode hergestellten Prăparaten, in dieser Gegend Fasern direkt zu dell inneren Haarzellen ziehen zu sehen, und an nach den Angaben Helds bearbeiteten Schnitten kann man auch bei den erwachsenen Săugern feine Fădchen verfolgen, die mit kleinen, blassen Varikositaten sich dem unteren Pol der inneren Haarzelle dicht anlegen (Fig. 21). Eine der $\mathrm{Held}$ schen entsprechende Neurosomenfärbung an dieser Stelle ist mir nie gelungen. Auch in dieser Gegend kommen, wenn auch nur in geringer Zahl, spiral verlaufende Nervenfasern vor. Die Hauptmasse der Fasern tritt aber zwischen den Innenphalangen und Innenpfeilern in den Tunnelraum ein. Auf diesem Wege weichen sie stark auseinander, so dass ein Teil in einem mehr spitzen, der andere in einem viel weniger spitzen Winkel zur Membrana basilaris mehr im oberen Teil des Tunnels verlauft (Fig. 6, 7, 45). Die unteren Fasern kreuzen dann jenseits des Tunnels die äusseren Pfeiler und die Deitersschen Zellen im unteren Drittel, die mehr oberflächlich ziehende Lage im mittleren Drittel. Wie man am besten auf dickeren Schnitten beobachten kann, die parallel zur Membrana basilaris geführt werden, haben die höher oben gelegenen Fasern einen mehr radiären, die tiefer gelegenen einen vorwiegend zur Radiärrichtung schiefen Verlauf (46). Unterhalb des inneren Pfeilers, der Oberflăche seines basalen Protoplasmas dicht aufgelagert, findet sich ein spiralig verlaufender Zug, der bei verschiedenen Tieren sehr verschieden stark ausgebildet ist (Fig. 7). Der Verlauf der Fasern jenseits des Tunnels ist bei den grossen Săugern nur teilweise zu beobachten. Sie ziehen zwischen den Deitersschen Zellen oder biegen im Winkel um und ziehen an 
der Innenseite der Reihen der Deiterssischen Zellen in spiraler Richtung weiter. Die Querschnitte dieser spiralen Fasern sieht man, wie bekannt, der Kontur des Protoplasmas dieser Stützzellen auf Radiärschnitten als Punktreihe anliegen (Fig. 6). Auch ibre Ausbildung ist sehr ungleich bei verschiedenen Tieren. Was die Beziehung zu den ăusseren Haarzellen betrifft, so sind die Aufschlüsse, die wir bei grossen Săugern erhalten können, sehr ungenügend, da eine wirklich kontrastierende Färbung der Nerven am basalen Zellpol nicht zu erzielen ist. Das Herantreten der Nerven an die Haarzelle durch den Schlitz, den der Stützkelch nach innen offen lăsst, konnte ich bei den grossen Säugern nicht beobachten, während dies, wie Katz (24) und Held (20) es beschrieben, bei Nagern sehr oft von mir gesehen wurde. Es kann mit den jetzt bekannten Methoden nur bei Embryonen und ganz jungen Tieren mit wenig verknöchertem Petrosum über diese Verhăltnisse Aufschluss gewonnen werden. Dagegen lassen die grossen Săuger manche interessanten Einzelheiten hinsichtlich der Beziehungen der marklosen Fasern untereinanader und zu den Elementen des Cortischen Organs erkennen. Es stehen ja gerade in dieser Region die Fasern unter ganz ungewöhnlichen Bedingungen, indem sie nirgends ein Zwischen- oder Stützgewebe besitzen und teilweise ganz frei verlaufen. Ihre $\mathrm{Be}-$ ziehungen zu dem basalen Teil der Grenzzellen, der Innenphalangen und der Deitersschen Stützzellen sind so innige, dass man kaum unterscheiden kann, ob sie bloss in rinnenförmigen Vertiefungen in deren Protoplasma verlaufen oder tatsächlich streckenweise von ihrem Protoplasma eingehüllt werden. Letzteres würde den Angaben $\mathrm{Helds}$ über das embryonale Auswachsen der Achsenzylinder entsprechen.

Im Tunnelraum sind die Fasern am besten der Beobachtung zugänglich (Fig. 45); man erkennt an allen neben schwer zu unterscheidenden Fibrillen einen zarten, protoplasmatischen Belag, der an allen den Stellen kräftiger ausgebildet ist, wo die Faser in nächster Nähe eines anderen Gebildes verlăuft, so insbesondere an Teilungsstellen der Fasern findet sich ein kleines, dreieckiges Protoplasmaklümpchen, aber auch dort, wo die Fasern an den Pfeilern vorüberziehen, sind sie mit der die Pfeilerfasern umhüllenden protoplasmatischen Aussenschicht durch ein hyalines Klümpchen perifibrillarer Substanz verbunden. Ausser typischen, 
dendritenartigen Teilungen (Fig. 43, 45) von Fasern sieht man im Tunnelraum auf zur Membrana basilaris parallelen Schnitten auch das Zusammentreten und Verschmelzen von getrennt aus der Habenula perforata austretenden Fäserchen, auch eine netzartige Verbindung stärkerer, glatter Fasern durch dicht anliegende variköse ist nichts Seltenes (Fig. 45). An den Kreuzungspunkten erscheinen die Fasern wieder durch Protoplasmaklümpchen der Perifibrillärsubstanz verbunden. An diesen finden sich kleine, 1-2 $\mu$ grosse, scharf konturierte Körperchen, die wenig färbbar sind und keine innere Struktur zeigen. Diese Gebilde, die schon beschrieben wurden, als Kerne zu deuten, scheint mir mangels irgendwelcher deutlicher Chromatinstrukturen nnd bei ihren geringen Dimensionen nicht möglich. Bei Quellung durch schlechte Fixierung können sie allerlei Formen annehmen.

Was Verlauf und Aufzweigung der Fasern im Cortischen Organ betrifft, so bestätigen die neueren Methoden im wesentlichen dasjenige, was Ebner (14) in Köllikers Handbuch in der schematischen Zusammenfassung der früheren Ergebnisse dargestellt hat. Ich konnte dendritische Verzweigungen der vom Ganglion ausgehenden Fasern vor und gleich nach dem Austritt aus der Habenula perforata beobachten. Ebenso jene Fasern, die jenseits des Tunnels mit mehrfachen Knickungen an verschiedenen Spiralzügen Anteil nehmen und deren Verlauf ich schon in einer früheren Arbeit beschrieben habe (Fig. 43). Auch konnte ich Fasern durch das Ganglion spirale hindurchziehen sehen, welche anscheinend mit keiner Ganglienzelle in Verbindung traten und offenbar von weiter entfernten Zellen stammten. Von spiral verlaufenden Fasern lassen sich, abgesehen von den im Bereich der markhaltigen Fasern gelegenen; fünf Züge unterscheiden. Der innerste ist unter den inneren Haarzellen gelegen, er ist bei allen Tieren, die ich untersuchte, nur schwach entwickelt (Fig. 43). Ein weiterer Zug liegt innerhalb des Tunnels dem inneren Pfeiler, wo dessen Fussteil sich verjüngt, angeschmiegt; er ist bei manchen Tieren seiner geringen Ausbildung wegen leicht zu übersehen, bei anderen aber, speziell den Wiederkäuern, sehr kräftig entwickelt (Fig. 7, 45). Die jenseits des Tunnels gelegenen drei Strănge, deren innige Verbindung mit den Fussteilen der Deitersschen Zellen oben geschildert wurde, bilden entweder ein Band, das nur aus einer Reihe von Fasern besteht, 
oder es sind in dieses Band stellenweise dickere Stränge von Fasern eingeschaltet, ein Zustand, der, wie bekannt, beim Menschen, wo dicke, kompakte Stränge sich finden, besonders stark ausgebildet ist. Ich möchte noch nebenbei erwähnen, dass ich bei jungen Mäusen auch noch eine oder die andere Faser halb spiral, halb bogenförmig im Gebiete der Hensenschen Zellen verlaufen sah; ob solche Fasern, schliesslich im Bogen zurücktretend, doch mit äusseren Haarzellen in Verbindung treten, war mir nicht möglich, zu ermitteln (Fig. 44). Das Vorkommen solcher Fasern ist auch von Ichita $\mathrm{Kishi}$ (23) und $\mathrm{Held}$ (19) festgestellt worden.

Über das Verhältnis der Fasern zu den Haarzellen gibt in viel höherem Maße, als es bisher möglich war, die Methode von Cajal Aufschluss, wenn sie bei Embryonen und jungen Tieren angewendet wird. Wenn es auch wahrscheinlich ist, dass bei den einzelnen Saugern in bezug auf Details Verschiedenheiten bestehen dürften, so können doch die bei kleinen Säugern, speziell bei der Maus, bestehenden Verhältnisse als im wesentlichen bei allen Säugern gültig erscheinen, da ja auch die vestibularen Nerven der verschiedenen Säuger weitgehende Übereinstimmung zeigen.

Zur Untersuchung wurden Mäuseembryonen allen Alters verwendet, ferner neugeborene Măuse und solche aus den ersten Lebenswochen.

Gute Färbungen im Gebiete des Co r ti schen Organs erzielte ich mit beiden Modifikationen des Cajalschen Verfahrens bei Mausen vom $11 \mathrm{~mm}$ langen Embryo bis zum Alter von 20 Tagen. Beim ălteren, ausgewachsenen Tier lässt der Knochen nur partielles Gelingen der Färbung zu; aber man kann immerhin noch manches, insbesondere in Schnittserien senkrecht auf den Modiolus, erkennen. Bei der grossen Anzahl der gefärbten Elemente kann man natürlich nicht wie in Präparaten der Chromsilbermethode in ganz dicken Schnitten die Fasern auf grosse Strecken übersehen, immerhin lassen sich auch in $30-40 \mu$ dicken "Schnitten noch Achsenzylinder auf grössere Entfernung verfolgen. Schon zu einer Zeit, da das Cortische Organ noch einen nicht weiter differenzierten Epithelwulst darstellt (Embryonen von 8-11 mm) findet man die Achsenzylinder als feine Bündel vom Ganglion cochleare ausgehen. Bald werden die Fibrillen für sich getrennt, 
bald zusammenklebend als dicker Achsenzylinder gefärbt, und es ist nicht immer $\mathrm{zu}$ unterscheiden, ob parallel laufende, zarte Fibrillen zu einem oder zu mehreren Achsenzylindern gehören. Man kann immer nur einige wenige der gefărbten Fäserchen bis ins Epithel verfolgen, und zwar etwa bis zur Grenze des grossen und kleinen Epithelwulstes. Sie verschwinden hier, indem sie sich spitz zulaufend bis zur Unsichtbarkeit verjüngen. Knöpfchenartige Bildungen wurden nicht beobachtet. Die später im Gebiete der markhaltigen Fasern gelegenen Spiralzüge sind zu dieser Zeit schon deutlich entwickelt.

In späteren Stadien finden wir Fasern bis in die Gegend jener Epithelien vorgeschoben, die sich zu Haarzellen entwickeln. Ihr letztes sichtbares Ende ist immer vom unteren Zellpol noch durch einen ziemlichen Abstand getrennt. Zugleich sieht man in den inneren Haarzellen unterhalb des Kerns und den unteren Zellpol erfüllend, ein sehr dichtes Netzwerk von Fibrillen auftreten. Neben dem Kern und oberhalb desselben im Haarzellenkopf liess sich dasselbe erst bei neugeborenen Tieren deutlich darstellen (Fig. 38). Schliesslich finden wir Achsenzylinder und Zelle sich vereinigen, wie es bei Besprechung der Maculae und Cristae geschildert wurde. Derselbe Vorgang spielt sich später an den äusseren Haarzellen ab und zwar sind die basalen Partien der Canalis cochlearis den jeweils höheren in bezug auf diese Entwicklungsvorgänge, wie in bezug auf Differenzierung überhaupt, voraus. Diese Vorgänge dürften noch weit in das extrauterine Leben sich hinziehen, wie lange, ist natürlich nicht leicht $z u$ bestimmen. Die spiralen Faserzüge sind schon viel früher gut entwickelt. Dendritenbildung jenseits des Canalis cochlearis ist nur selten zu finden (Fig. 41); es ist nicht undenkbar, dass noch später die Bildung von Dendriten zustande kommt. Die ausgebildete Haarzelle enthălt dicht unter der Oberfläche ein engmaschiges Gitterwerk von Neurofibrillen. Die Maschen sind oberhalb des Kernes lang und schmal, unterhalb des Kernes eng und rundlich, letztere werden selten rein imprăgniert, verkleben häufig und sehen dann wie ein kompakter Körper aus; die Fibrillen des Achsenzylinders gehen in das basale Gitter direkt über (Fig. 40, 41, 42).

Nur in frühen Stadien (Embryonen bis $15 \mathrm{~mm}$ ) findet man auf Radiärschnitten durch die Schnecke einzelne Achsen- 
cylinder im Gebiete des grossen Epithelwulstes nach innen von den inneren Haarzellen gelegen. Diese Achsencylinder lassen sich bei der späteren Entwicklung nicht mehr konstatieren und gehen vielleicht wieder zu Grunde; ob sie bei einer phylogenetisch älteren Form vorhanden sind, ist fraglich.

Was die Ganglienzellen des Ganglion spirale betrifft, so möchte ich sie bei einer anderen Gelegenheit zum Gegenstande einer besonderen Untersuchung machen. Hier soll nur erwähnt werden, dass sich manchmal sowohl mit Osmium und Holzessig, als insbesondere mit Hilfe der Kalibichromat-Formol-EisessigFixierung und Eisenhämatoxylin eine ziemlich kräftige, innerhalb der bindegewebigen Kapsel gelegene Markscheide darstellen lässt, die, der Oberfläche der Ganglienzelle dicht anliegend, von der Kapsel durch einen vielleicht durch Kunstprodukt entstandenen Spaltraum getrennt erscheint. In anderen Fallen lässt sich wieder von einer Markscheide nichts nachweisen. Gegen die Markscheide der Faser ist die Markscheide der Zelle durch eine den Ranvierschen Einschnürungen entsprechende Bildung abgegrenzt. Die Neurofibrillen der ein- und austretenden Fasern sind viel weniger zahlreich als die in der Zelle befindlichen; Teilungen und Netzbildung derselben ist daher höchst wahrscheinlich. Pigment in den Nervenzellen ist selten.

Wenn wir die Resultate vorliegender Untersuchung zusammenfassen, so ergibt sich:

Das Gehörorgan der grösseren Săuger entspricht in anatomischer und cytologischer Hinsicht ziemlich genau der Schilderung, welche die Autoren von dem Gehörorgan kleinerer Säuger gegeben haben.

Bei allen untersuchten Tieren lassen sich im wesentlichen die von $\mathrm{Held}$ beschriebenen Stützapparate im Cortischen Organ nachweisen und deren mit der Windung sich andernde Ausbildung. Diese Stützapparate zeigen bei den einzelnen Tieren verschiedene charakteristische Eigentümlichkeiten; im wesentlichen ist aber ihre Struktur überall dieselbe.

Das von Held zuerst beschriebene Zellelement, die Innenphalange, sowie die sogenannte Grenzzelle ist auch bei den grösseren Säugern vorhanden. Es lassen sich in diesen Zellen Stützfaserstrukturen nachweisen. Bei den Wiederkäuern bestehen mehrere Reihen von Grenzzellen. 
Dagegen gibt es bei guter Fixierung Elemente, welche den "kleinen Körnern" der Autoren entsprechen, nicht. Durch das Zusammenwirken aller Stützelemente erscheinen die Sinneszellen nicht nur aufgehăngt, sondern an beiden Enden befestigt und fast vollkommen frei in der Endolymphe ausgespannt und vor gegenseitiger Annăherung geschützt. Eine gelenkige Verbindung der Pfeilerzellen scheint ausgeschlossen.

Was die Haarzellen selbst betrifft, so kann man an ihnen ausser der differenzierten Kopfplatte und deren Einschluss jenen Körper unterscheiden, der als Hensenscher Körper bekannt ist; er scheint in die Kategorie jener intrazellularen Gebilde zu gehören, die man als Trophospongien bezeichnet.

Das Protoplasma aller Sinneszellen erscheint bei gelungener Fixierung nicht homogen; es enthält fibrilläre Elemente. Die neueren Silbermethoden zeigen diese Fibrillen als Netze und Gitter angeordnet, die in die Fibrillen der Nerven direkt übergehen.

Dies gilt für alle Sinneszellen des Labyrinths. Der sogenannte Retziussche Körper in den ăusseren Haarzellen dürfte einer Verdichtung des Fibrillennetzwerkes entsprechen.

Was die Innervation des Labyrinths der Säuger betrifft, so lässt sich auch hier die Versorgung mit zweierlei Fasern feststellen, wie sie von Cajal beim Hühnerembryo für die Cristae beschrieben wurden. 1. Dicke Fasern, deren Neurofibrillen mit den Neurofibrillen der Sinneszelle zusammenbängen, 2. dünne, schwer darzustellende Fasern, deren Fibrillen an der Peripherie in einem Endknopf umbiegen und den freien Endigungen im Epithel überhaupt entsprechen.

Diese Verhältnisse gelten für Maculae und Cristae. Fibrillen desselben Achsenzylinders verbinden sich häufig mit Fibrillen verschiedener Sinneszellen, aber auch Fibrillen derselben Zelle konnten mit Sicherheit in Verbindung mit Fibrillen verschiedener Axone nachgewiesen werden.

Die Verbindung zwischen Zelle und Achsenzylinder scheint nach den bisherigen Ergebnissen der Untersuchung an Embryonen dadurch zustande zu kommen, dass die im Achsenzylinder und in der Sinneszelle ursprünglich getrennten Fibrillen durch Verwachsung $\mathrm{zu}$ einer Kontinuität werden. Ein Einwachsen von Fibrillen vom Achsenzylinder in die Zelle erscheint ausgeschlossen, ebenso ein Auswachsen der Achsenzylinder aus der Sinneszelle. 
Es dürfte somit am Platze sein, die Sinneszellen des Labyrinths als periphere Nervenzellen aufzufassen und eine sekundäre Verschmelzung ihrer Fibrillen mit denen eines entgegenwachsenden Achsenzylinders anzunehmen. Man müsste denn die umstrittene Behauptung annehmen, dass die Ganglienanlage des Labyrinths aus dem Labyrinthbläschen und nicht aus der Ganglienleiste sich entwickle, und auf diese Weise von vornherein im Sinne Hensens kontinuierliche Zellzusammenhänge vorhanden seien, die durch ihre Feinheit jenseits des Bereichs unserer Methoden und optischen Hilfsmittel gelegen wären. Dieser Punkt, vor allem die Anlage der Labyrinthganglien, bedarf noch eingehender Aufklärung. Ich möchte nebenbei bemerken, dass ich bei Anstellung der Untersuchung am wenigsten an die Möglichkeit des so rätselhaften Auswachsens der Achsenzylinder geglaubt habe, viel eher an das Vorhandensein einer Zellikette wie sie speziell Dhorn bei den Lorenzinischen Ampullen der Selachier beschrieben hat, dass aber die Bilder der $\mathrm{C}$ ajal schen Methode eine solche Deutung kaum zulassen dürften, wenigstens was die Strecke der nervösen Verbindung innerhalb der Anlage des Cortischen Organs betrifft. Auch das vollständige Fehlen von Zellkernen auf dieser Strecke der Nerven im ausgebildeten Organ würde eine solche Deutung der Entstehung der Achsenzylinder wenigstens an diesem Orte viel gezwungener erscheinen lassen, als die Annahme von auf dieser Strecke auswachsenden Achsenzylindern.

Was die Verwertung der histologischen Befunde zur Stütze einer der bestehenden Hörtheorien betrifft, so hat schon E b n er (14) in ausgezeichneter Weise die Tatsachen erörtert, welche derzeit uns veranlassen, eine andere Erklärung für. die Wirkungsweise des Cortischen Organs zu suchen, als es die Helmholtzsche Theorie annahm. Ich möchte hier nochmals betonen, dass die besonders innige Vereinigung aller Teile des Cortischen Organs und der Membrana basilaris untereinander und das Fehlen isolierter Leitungen (19), das auch mit den neueren Methoden besonders zutage tritt, dieser Theorie widerspricht. Was die Längenverhältnisse der Fasern der Membrana basilaris betrifft, deren Verhalten in neuerer Zeit für und gegen die Gültigkeit der Helmholtzschen Theorie wiederholt ins Feld geführt wurde, so zeigen die $\mathrm{MaBe}$, die wir bei den Haustieren finden, ungefăhr dasselbe Verhalten, wie es von den sonst untersuchten Saugern 
bekannt ist. Bei der Suche aber nach anderen "abgestimmten" Resonatoren, ganz im allgemeinen von gleichartigen Objekten verschiedener Dimension, finden wir auf jedem Radiärschnitt alle Elemente des Cortischen Organs dem nächst tiefer gelegenen an Grösse überlegen und zwar in ganz beträchtlichem Maße. Insbesondere zeigen es die Haarzellen. Dieses muss um so mehr auffallen, da wir gewohnt sind, bei gleichartigen Zellen, die ein Organ zusammensetzen, und ganz besonders in Sinnesorganen wenig Grössenunterschiede zu finden. Weist doch schon die frühe Anlage, die besondere Struktur, die ganz exceptionelle Verbindung mit anderen Zellen durch "Ausspannung" darauf hin, dass wir hier den eigentlichen Sitz der Umwandlung der Energie der Aussenwelt in den "nervösen" Prozess zu suchen haben. Und da doch ohne Zweifel diese Vorgänge Stoffwechselvorgänge sind, so erscheinen gerade wieder die Haarzellen durch ihr fast allseitiges Umgebensein mit Endolymphe zu raschen Stoffwechselvorgängen besonders prädestiniert. Auch ihre postmortale Vergänglichkeit erlaubt uns, auf die Labilität ibres Protoplasmas im Leben zurückzuschliessen. Das Bestehenbleiben eines dem als Stoffiwechselorgan der Zelle gedeuteten Trophospongium ähnlichen Gebildes, das in den anderen Zellen des Ductus cochlearis sich zurückbildet, kann diese Ansicht nur fördern. Die verschiedene Länge der Hörhaare in verschiedenen Höhen des Cor tischen Organs entspricht nicht vollkommen der Verschiedenheit der Längsdimension dieser Zellen. Die von $\mathrm{Held}$ zuerst richtig beschriebene Form und Anordnung der Haare konnte ich vollkommen bestätigen, möchte aber noch nicht entscheiden, ob die immerhin geringe Längendifferenz dieser Gebilde uns berechtigt, etwa in ihnen, wie $\mathrm{Held} \mathrm{(20)}$ in Anlehnung an Vorstellungen Hensens es andeutet, die gesuchten „abgestimmten Resonatoren zu sehen. Ein freies Schwingen erscheint bei ihnen in den Fällen, wo sie mit der Membrana tectoria durch Fädchen verbunden sind, stark in Frage gestellt. Dass die Hörhaare aber und die Membrana tectoria bei der Erregung der Haarzellen eine Rolle spielen, ist nach dem geschilderten Lageverhältnis mehr als wahrscheinlich.

Besonders aber soll betont werden, dass die ganz auffallende Ausspannung der Haarzellen darauf hindeutet, dass auch der Spannungszustand derselben eine wichtige Rolle beim Entstehen der Gehörsempfindung spielen dürfte. 
Was die neueren Erklärungsweisen der Funktion der Papilla basilaris betrifft, speziell die Ausführungen $Z$ w a ar de m a ke rs (47) und ter Kniles (31), so möchte ich mich auf eine năhere Erörterung dieser Theorien nicht einlassen, vor allem, da ich der Überzeugung bin, dass die tatsächlich intra vitam bestehenden physikalischen Eigenschaften der hier in Betracht kommenden Elemente noch lange nicht soweit sicher bekannt sind, um eine derartige physikalische Behandlung zu erlauben. Immerhin aber soll hier bemerkt werden, dass meine Befunde in jeder Hinsicht eher die Ansicht ter Kuiles (32) zu stützen geeignet sind. Speziell erscheint mir ein Gedrücktwerden der Haarzellen durch die anderen Elemente des Cortischen Organs vollkommen ausgeschlossen, ihre Erregung von den Hörhaaren aus oder durch Veränderungen in ihrem Ausspannungszustand viel naheliegender. Es ist recht wahrscheinlich, dass bei allen denkbaren Massenverlagerungen innerhalb des Ductus cochlearis die Membrana basilaris samt dem Cortischen Organ und die Membrana tectoria in gleicher Richtung verlagert werden dürften, durch ihre verschiedene Spannung und Trägheit dürften sie aber immerhin gegeneinander verlagert werden, was jedenfalls im Spannungszustand der Haarzellen Verănderungen herbeiführen muss.

Verlagerungen im Cortischen Organ im Sinne einer tatsächlichen Gelenkbewegung zwischen den Pfeilern sind durch deren Verkittung nicht denkbar, Bewegungen im selben Sinne aber durch die Elastizität der äusseren Pfeiler erklärbar.

Bei der Untersuchung des Hörvorganges wird man wohl den Hörhaaren neuerdings seine Aufmerksamkeit widmen müssen, aber nicht nur den Verhältnissen in der Cochlea. Auch die Einrichtungen in den Maculae und Cristae, deren Verhältnisse in der letzten Zeit fast nur mehr vom Standpunkte ihrer Funktion zur statischen Orientierung betrachtet wurden. Deuten doch die interessanten Versuche von Piper (38) darauf hin, dass diese Endorgane nicht so ganz unbeteiligt am Hörakte sind, als es die Mehrzahl der Physiologen entgegen dem Standpunkte von Hensen anzunehmen geneigt waren.

Wien, Januar 1907. 


\section{Literaturverzeichnis.}

1. Alexander: Das Labyrinthpigment des Menschen und der höheren Sängetiere. Arch. f. mikr. Anat., Bd. 58, 1901.

2. Alexander und J. Tandler: Untersuchungen an kongenital tauben Hunden etc. Arch. f. Ohrenheilk., Bd. 64, 1905.

3. Ayers: On the Membrana basilaris, the membrana tectoria and the nerveendings of the human ear. Zoological Bulletin, Boston, Vol. 1, p. $27 \check{5}$ (Journal of Morphology, Vol. 6, 1892.

4. Bielschofski: Die Silberimprägnation der Neurofibrillen. Neurol. Zentralbl., 1903.

5. Derselbe: Die Darstellung der Achsenzylinder peripherer Nervenfasern und der Achsenzylinder zentraler. markhaltiger Nervenfasern. Journ. f. Psych. u. Neurol., Bd. 4, 1905.

6. Böttcher: Über Entwicklung und Bau des Gehörlabyrinths. 1869.

7. Cannieu: Journal de l'anatomie et physiologie. Paris, 35. ann., p. 1.

8. Ramon y Cajal: Trabajos del Labor de Investigaciones biologicas. Univ. Madrid, 1903, 1904, 1905.

9. Carl: Beiträge zur Morphologie des Utriculus und Sacculus und ihrer Anhänge bei den Sängetieren. Anatomische Studien, herausg. v. Hasse, Bd. 1, 4. Heft, Leipzig 1873.

10. Deiters: Untersuchungen über die lamina spiralis membranacea. Bonn 1860.

11. Denis: Archives de Biologie, Tome 18.

12. Denker: Vergleichende anatomische Untersuchungen über das Gehörorgan der Säugetiere nach Corrosionspräparaten und Knochenschnitten. Leipzig 1899.

13. Dupuis: Die Cortische Membran. Anatomische Hefte, Bd. 3.

14. Ebner-Kölliker: Handbuch der Gewebelehre des Menschen, 190203.

15. Ebner: Bericht d. naturw.-med. Ver. in Innsbruck, 1872.

16. Engelmann: Funktion der Otulithen. Zoolog. Anzeiger, Bd. 10, 1881.

17. Ferré: Contribution à l'étude du nerf auditif. Bulletin de la Société de Zoologie de France.

18. Gottstein: Über den feineren Bau und die Entwicklung der Gehörschnecke bei Menschen und den Säugern. Arch. f. mikr. Anat., Bd. 8, 1872.

19. Held: Archiv f. Anat. u. Phys., 1897.

20. Derselbe: Untersuchungen über den feineren Bau des Ohrlabyrinths der Wirbeltiere. (Zur Kenntnis des Cortischen Organs und der übrigen Sinnesapparate des Labyrinths der Säuger.) Abhandlungen der mathematisch-physikalischen Klasse der sächsischen Gesellschaft der Wissenschaften, Leipzig, Bd. 28.

21. Hensen: Zur Morphologie der Schnecke des Menschen und der Säugetiere. Zeitschrift für wissenschaftl. Zoologie, Bd. 13, 1863.

22. Joseph, H.: Zur Kenntnis vom feineren Bau der Gehörschnecke. Anat. Hefte, Bd. 46, 1900. 
23. Ichita-Kishi: ت̈ber den Verlauf und die periphere Endigung des Nervus cochlearis. Arch. f. mikr. Anat., Bd. 56, p. 144.

24. Katz: Über die Endigung des Nerrus cochlearis im Cortischen Organ. Arch. f. Ohrenheilkunde, 1896.

25. Derselbe: Beiträge zur Frage über die Verbindung der Cortischen und Deitersschen Zellen und deren Gestalt. Monatsschrift f. Ohrenheilkunde, 1888.

26. Kolmer: Über die Endigungsweise des Nervus octavus. Zentralbl. f. Physiol., 1904.

27. Derselbe: Über das Verhalten der Neurofibrillen an der Peripherie. Anat. Anz., Bd. 26, 1905.

28. Derselbe: Zur Kenntnis des Verhaltens der Neurofibrillen an der Peripherie. Anat. Anz., Bd. 27, 1905.

29. Krause, R.: Handbuch der Entwicklungsgeschichte der Wirbeltiere.

30. Derselbe: Die Endigungen des Nervus acusticus im Gehörorgan des Flussneunauges. Sitzungsber. d. preuss. Akad. d. Wissenschaften, Bd. 48, 1905.

31. E. ter Knile: Die richtige Bewegungsform der Membrana basilaris. Pflügers Archiv, Bd. 79, p. 484.

32. Derselbe: Zur Funktion der Papilla acustica basilaris. Arch. f. Physiol., 1906, p. 127.

33. Lavdowsky: Archiv f. mikr. Anatomie, Bd. 13, 1877.

34. Lenhossék: Beiträge zur Histologie des Nervensystems und der Sinnesorgane, 1894.

35. London: Archiv f. mikr. Anatomie, Bd. 66, 1905.

36. London und Pesker: Archiv f. mikr. Anatomie, Bd. 67, 1906.

37. Mann: Physiological Histology, 1902.

38. Piper: Physiologisches Zentralbl., 1906.

39. Prenant: Internat. Monatsschrift f. Anatomie u. Physiologie, Bd. 9.

40. Retzius: Das Gehörorgan der Wirbeltiere. 1881.

41. Derselbe: Biologische Untersuchungen. I, III, V, IX, XII.

42. Rickenbacher: Untersuchungen über die embryonale Membrana tectoria des Meerschweins. Anatom. Hefte, Bd. 16.

43. Schulze, Max: Über die Endigungsweise des Hörnerven im Labyrinth. Müllers Archiv, 1858.

44. Spee: Mitteilungen zur Histologie des Cortischen Organs und der Gehörschnecke des erwachsenen Menschen. Verhandlung der anat. Gesellschaft. Bonn 1901 und Münchener mediz. Wochenschrift, 1902, Heft 3.

45. Waldeyer: Strickers Handbuch der Gewebelehre, 1872.

46. Wulf: ẗber die Dimensionen des Bogengangsystems bei den Wirbeltieren. Arch. f. Anat. u. Phys., 1901, p. 57.

47. Zwaardemaker: Über den Schalldruck im Cortischen Organ als den eigentlichen Gehörreiz. Arch. f. Physiol., 1905̃, Supplementbd., 1. Hälfte. 


\section{Erklärung der Abbildungen auf Tafel XXXVII-XL.}

Die Abbildungen wurden mit Hilfe des $\mathrm{Z}$ e is s - $\mathrm{A}$ b b é schen Zeichenapparates hergestellt.

Fig. 1. Radiärschnitt durch die Schnecke eines Schweins. KalibichromatFormol-Eisessig-Fixation. Eisenhämatoxylin nach Heidenhain. Zeiss' Achromat as Ok. 4.

Fig. 2. Querschnitt durch den Boden des Canalis cochlearis vom Schwein. Anfang der Basalwindung. Fixierung und Färbung wie Fig. 1. Zeiss' Apochr. $4 \mathrm{~mm}$ Ok. 4.

Fig. 3. Der entsprechende Querschnitt aus der zweiten Windung; sonst wie Fig. 2.

Fig. 4. Der entsprechende Querschnitt aus der dritten Windung; sonst wie Fig. 2.

Flg. j. Radiärschnitt durch die Basalwindung des Cortischen Organs eines ausgewachsenen Schweines. Kalibichromat-Formol-Eisessig-Fixierung. Eisenhämatoxylin. Zeiss' Aprochromat 1,40, Apert. 2 mm, Kompens.-Ok. 12.

Fig. 6. Radiärschnitt durch die Basalwindung des Cortischen Organs einer 6 Monate alten Ziege. Färbung, Fixierung und Vergrösserung wie Fig. 5 .

Fig. 7. Radiärschnitt durch das Cortische Organ der zweiten Windung eines halbjährigen Kalbes. Färbung und Fixierung wie Fig. 5. Zeiss' Aprochr. 1,40, Apert. $3 \mathrm{~mm}$, Kompens.-Ok. 6.

Fig. 8. Vier Aussenpfeiler vom Schwein, aus einer Schnittserie parallel zum Modiolus, vom Tunnelraum her gesehen. Bei a Zusammenhang der Stützfasern in Kopf und \Phalangenfortsatz. Fixierung und Fortsatz wie Fig. 5. Zeiss' Apochromat 1,40. Apert. $2 \mathrm{~mm}$. Kompens.-Ok. 12.

Fig. 9. Aus einer senkrecht auf den Modiolus geführten Schnittserie vom Schwein, Köpfe von inneren Haarzellen (I. H.) mit Innenphalangen und Grenzzellen, Köpfe der ersten äusseren Haarzellenreihe; Strukturbild der Pfeilerköpfe von oben gesehen. Fixierung und Färbung wie Fig. 5. Zeiss' Apochr. 1,40. Apert. 2 mm, Kompens.-0k. 12.

Fig. 10. Aus einem Radiärschnitt durch das Cortische Organ des Schweins zweite Windung. Verbindung und Struktur der Pfeilerköpfe. Sonst wie Fig. 9.

Fig. 11. Aus einer Schnittserie senkrecht auf den Modiolus. Flachschnitt durch die Pfeilerköpfe, Kopfplatten der inneren Haarzellen und Innenphalangen. Fixierung, Färbung und Vergrösserung wie Fig. 9.

Fig. 12. Aus einer Schnittserie senkrecht auf den Modiolus. Links mehr oben, rechts tiefer durchschnittene Pfeilerköpfe, äussere und innere Haarzellen. Sonst wie Fig. 9.

Fig. 13. Doppelte Innenphalange zwischen zwei inneren Haarzellen. Sonst wie Fig. 9. 
Fig. 14. Aus einer Schnittserie senkrecht auf den Modiolus. Drei innere Haarzellenköpfe mit Innenphalangen und Grenzzellen. Stützfaserbildung in den Grenzzellen. Sonst wie Fig. 9.

Fig. 15. Deiterssche Zelle in Verbindung mit geschrumpfter Haarzelle aus einem Schiefschnitt des Cortischen Organs vom Schwein. $Z_{W}$ eite Windung; der Fortsatz zum oberen Kopf entspringt aus dem Stützkelch. Sonst wie Fig. 9.

Fig. 16. Obere Hälfte einer Deitersschen Stützzelle samt Haarzelle, der obere Fortsatz zum oberen Kopf entspringt unterhalb des Kelches. Sonst wie Fig. 9.

Fig. 17. Deiterssche Stützzelle, die zwei Stützkelche bildet. Zeiss' Apochr. 1,40 , Apert. $3 \mathrm{~mm}$, Kompens.-Ok. 6 .

Fig. 18. Deiterssche Stützzelle vom Schwein aus dem Beginn der zweiten Windung. Kalibichromat-Formol-Eisessig-Fixierung. Helds Beize. Eisenhämatoxylin. Zeiss' Apochr. 1,40, Apert. 2 mm, Kompens.-Ok. 6.

Fig. 19. Äusserste, bogenbildende Deiterssche Stützzelle aus der Mitte der zweiten Windung des Cortischen Organs vom Schwein. Schnitt nicht vollständig radiär. Sonst wie Fig. 18.

Fig. 20. Totopräparat des Cortischen Organs vom Schwein von oben gesehen. Osmium Glycerin. Zeiss' Apochromat 1,40, Apert. $3 \mathrm{~mm}$, Kompens.-Ok. 8.

Fig. 21. Aus einem Radiärschnitt durch die zweite Windung des Cortischen Organs vom Schwein, Innere Haarzelle mit an sie herantretenden, marklosen Fasern, fibrilläre Strukturen im Innern der Haarzelle. Struktur der Pfeilerköpfe. Zeiss' Apochromat 1,40, Apert. 2 mm, Kompens.-Ok. 12.

Fig. 22. Äussere Haarzelle, aus dem Ende der zweiten Windung vom Schwein. Fibrilläre Strukturen. glatte Zellmembran, Retziusscher Körper. Vergr. wie Fig. 21.

Fig. 23. Aus einem Schiefschnitt des Cortischen Organs. Ende der Basalwindung. Umfassung der Basalteile der äusseren Haarzellen durch die Stützkelche. Vergr. wie Fig. 21. J

Fig. 24. Drei äussere Haarzellen vom Meerschwein. Struktur der Hensenschen Körper. Fixation und Entkalkung in Trichloressigsäure. Eisenhämatoxylin. Vergr. wie Fig. 21.

Fig. 25. Aus einem Schiefschnitt des Cortischen Organs. Drei Köpfe innerer Pfeiler, zwei Köpfe von inneren Haarzellen, teilweise angeschnitten. Struktur und Insertion der Hörhaare vom Schwein. KalibichromatFormol-Eisessig-Fixation. Eisenhämatoxylin. Vergr. wie Fig. 21.

Fig. 26. Schnitt ungefähr durch die Mitte einer Crista ampullaris vom Schwein. Fixierung wie Fig. 25. Zeiss' Apochr. 4 mm, Kompens.-Ok. 4.

Fig. 27. Deiterssche Stützzelle vom Rind. Zweite Windung. Einschlusskörper. Zeiss' Apochr. 1,40, Apert. 2 mm, Kompens.-Ok. 6.

Fig. 28. Aus einem Schnitt, senkrecht auf den Modiolus vom Rind. Köpfe von drei inneren Haarzellen, umfasst von den Köpfen der Pfeiler, 
den Innenphalangen und mehreren Reihen kleinerer Grenzzellen. Zeiss' Apochr. Apert. 1,40, 2 mm, Kompens.-Ok. 8.

Fig. 29. Sinneszelle in Verbindung mit einer Nervenfaser und Stützzellen aus einem Schnitt durch die Höhe der Crista ampullaris vom Pferd. Kalibichromat-Formol-Eisessig-Fixierung. Eisenhämatoxylin. Vergr. wie Fig. 28.

Fig. 30, Querschnitte von postganglionären Nervenfasern vom Pferd. A aus der Crista ampullaris, B aus dem Cortischen Organ. Osmium, Rubin. Zeiss' Apochr. 2 mm, Apert. 1,40, Kompens.-Ok. 18.

Fig. 31. Schnitt durch die Höhe der Crista ampullaris der erwachsenen Katze. Cajals Methode. Fibrillen der Haarzellen mit den Fibrillen der dicken Achsenzylinder in Kontinuität. Mehrere Zellen von einer Faser mit Fibrillen versorgt. Zarte Fasern des zweiten Typus; die eigentliche freie Endigung nicht im Schnitte zu sehen. Zeiss' Apochr., Apert. 1.40, 2 mm, Kompens. -0k. 8.

Fig. 32. Haarzelle aus der Crista ampullaris der erwachsenen Katze. Fibrillengitter in der Zelle in Zusammenhang mit den Fibrillen des Achsenzylinders. Die oberhalb des Kerns gelegene Calotte des Zellkörpers weggeschnitten. Schnittdicke $4 \mu$. Cajals Methode. Silber-Fixation. Zeiss' Apochr., Apert. 1.40, 2 mm, Kompens.-Ok. 18.

Fig. 33. Schnitt durch die Macula utriculi von neugeborenen Menschen. Färbung und Vergrösserung wie 32. (Material vier Stunden post mortem fixiert).

Fig. 34. Schnitt durch den peripheren Teil der Crista ampullaris eines vierzigjährigen Mannes. Cajals Methode. Material sechs Stunden post mortem fixiert. (Postmortale Veränderungen.) Apochr. 1.40, $2 \mathrm{~mm}$, Ok. 12.

Fig. 35. Aus einem Schnitt durch die Crista acustica eines Kalbes. Cajals Methode. Verbindung von Fibrillen zweier Achsenzylinder mit einer Sinneszelle. „Arkadenbildung". Zeiss' Apochr. 1.40, 2 mm, 0k. 12. (Material 15 Minuten post mortem fixiert.) Schnittdicke $6 \mu$.

Fig. 36. Schnitt durch die Macula sacculi eines 10,5 mm langen Mausembryos. Das Fibrillengitter entwickelt sich im basalen Anteil der Zelle. Fibrillen der Achsenzylinder erst stellenweise damit im Zusammenhang darstellbar. Schnittdicke $6 \mu$.

Fig. 37. Aus einem Schnitt durch die Crista ampullaris eines $10,5 \mathrm{~mm}$ langen Mausembryos. Entwicklung des Fibrillengitters in der oberen, peripheren Partie einer Sinneszelle. Cajals Methode mit ammoniakalischem Alkohol. Zeiss' Apochr. 1,40, 2 mm, Kompens.-Ok. 18.

Fig. 38. Aus einem Schnitt senkrecht auf den Modiolus der Schnecke einer neugeborenen Maus. Vier innere Haarzellen der Länge nach getroffen. Fibrillengitter, basale Verdichtung desselben zu stark imprägniert. Achsenzylinderfibrillen. Cajals Methode mit SilberFixation. Vergr. wie 37. 
Fig. 39. Zwei Zellen aus der zweiten Reihe der äusseren Haarzellen. Neugeborene Maus. Cajals Methode. Durch teilweise Färbung des Fibrillengitters kommt die Form eines basalen Kelches mit Fortsätzen zustande. Vergr. wie 37.

Fig. 40. Schiefschnitt durch das Cortische Organ eines Mäuschens von sieben Tagen. Teilweise Darstellung des Neurofibrillengitters in inneren und äusseren Haarzellen. Die Fibrillen liegen der Kernoberfläche ganz nahe. Spiralfasern. Apochr. 1,40, $2 \mathrm{~mm}, 0 \mathrm{k} .8$.

Fig. 41. Aus einem zum Modiolus parallelen Schnitt durch das Cortische Organ einer 20 Tage alten Maus. Haarzellen der äussersten Reihe überfärbt im Zusammenhang mit Achsenzylinderfibrillen. Dendritische Aufzweigung eines Achsenzylinders. Apochr. 1,40, $2 \mathrm{~mm}, 0 \mathrm{k} .12$.

Fig. 42. Aus einem Schiefschnitt durch das Cortische Organ einer neugeborenen Maus. Gitterbildung in den äusseren Haarzellen. Spiralfasern. Cajalsche Methode mit ammoniakalischem Alkohol. ZeissApochr. 1,40, $2 \mathrm{~mm}, 0$ k. 6 .

Fig. 43. Schnitt senkrecht auf den Modiolus. Neugeborene Maus. Faserverlauf im Gebiete der inneren und ersten äusseren Haarzellenreihe (Schnittdicke $10 \mu$ ). Innere und äussere Spiralfasern. Dendritenbildung im Tunnel etc. Apochr. 1,40, $2 \mathrm{~mm}$, Ok. 12.

Fig. 44. Schnitt entsprechend dem vorigen. Verlauf der die äusseren Spiralzüge bildenden Fasern. 2, 1,40 mm, Ok. 8, Cajals Methode.

Fig. 45. Schnitt senkrecht auf den Modiolus der Schnecke des Kalbes. Längsschnitt durch den Tunnelraum. (Schnittdicke $15 \mu$ ). In dieser Figur sind bei verschiedener Finstellung sichtbare Fasern in einer Ebene eingetragen, die dickeren, mehr geradlinigen, dunkler gezeichneten Fasern sind höher liegend zu denken. Man sieht sowohl getrennt aus der Habenula perforata austretende Fasern im Tunnelraum zu einer gemeinsamen Faser zusammentreten als auch Fasern, die vor dem Herantreten an die drei Reihen der Deitersschen Zellen, deren basale Teile mit den Stützfasern quer getroffen erscheinen, dendritisch sich teilen. Zeiss' Apochr. 1,40, Apert. 3 mm, Kompens.Ok. 6. Sonst wie 29.

Fig. 46. Schnitt parallel zum Modiolus durch das Cortische Organ der Ziege. Der Schnitt verläuft hauptsächlich durch die erste Reihe der Deitersschen Stützzellen und Haarzellen und zeigt die Anordnung des an die erste Reihe der Deitersschen Zellen sich anlegenden Spiralfaserzuges. Bei A liefert eine Faser, die den Tunneiraum durchsetzt hat, durch dendritische Teilung drei nach einer Seite hin in verschiedenen Höhen verlaufende Spiralfasern. Apochr. 1,40,3 mm, Ok. 4. Sonst wie 29.

Fig. 47. Dendritische Aufteilung einer Tunnelfaser an der innersten Deitersschen Zelle mit Übergang in zwei verschieden hoch verlaufende Spiralfasern. Schwein. Zeiss' Apochr. 1,40, Apert. 2 mm, Ok. 6, Technik wie 29. 
Fig. 48. Verbindung der Hörhaare der drei äusseren Haarzellen mit der Membrana tectoria; aus einem Radiärschnitt durch die Schnecke eines ausgewachsenen Schweines. Zeiss' Apochr. $2 \mathrm{~mm}$, Apert. 1,40, Ok. 6, Technik wie 29.

Fig. 49. Schiefschnitt durch den Rand des Limbus spiralis. Übergang der Epithelzellen des sulcus spiralus internus in die auf dem Limbos versenkten Epithelien. Technik wie 29.

Fig. อ0. Schiefschnitt durch die Membrana tectoria vom Schwein. Zeiss' Apochr. 3 mm, Apert. 1,40, Ok. 4, Technik wie 29.

Die Figuren 1, 2, 3, 4 sind auf $3 / 4$, die Figuren 5,67 u. 46 auf $1 / 2$ des Originals reduziert. 